\title{
Comparative analyses of morphological characters in Sphaerodoridae and allies (Annelida) revealed by an integrative microscopical approach
}

\author{
Conrad Helm ${ }^{1 *}$ and María Capa ${ }^{2}$ \\ ${ }^{1}$ Faculty of Biosciences, Pharmacy and Psychology, Institute of Biology, University of Leipzig, Leipzig, Germany \\ ${ }^{2}$ Department of Natural History, University Museum, Norwegian University of Science and Technology, Trondheim, Norway
}

Edited by:

Greg W. Rouse, University of

California, San Diego, USA

\section{Reviewed by:}

Helena Wiklund, Natural History

Museum, UK

M. Teresa Aguado Molina,

Universidad Autónoma de Madrid, Spain

*Correspondence:

Conrad Helm, Molecular Evolution and Animal Systematics, Institute of

Biology, University of Leipzig,

Talstraße 33, 04103 Leipzig,

Germany

e-mail:helm@uni-leipzig.de

\begin{abstract}
Sphaerodoridae is a group of benthic marine worms (Annelida) characterized by the presence of spherical tubercles covering their whole surface. They are commonly considered as belonging to Phyllodocida although sistergroup relationships are still far from being understood. Primary homology assessments of their morphological features are lacking, hindering the appraisal of evolutionary relationships between taxa. Therefore, our detailed morphological investigation focuses on different Sphaerodoridae as well as on other members of Phyllodocida using an integrative approach combining scanning electron microscopy (SEM) as well as immunohistochemistry with standard neuronal (anti-5-HT) and muscular (phalloidin-rhodamine) markers and subsequent CLSM analysis of whole mounts and sections. Furthermore, we provide histological (HES) and light microscopical data to shed light on the structures and hypothetical function of sphaerodorid key morphological features. We provide fundamental details into the sphaerodorid morphology supporting a Phyllodocida ancestry of these enigmatic worms. However, the muscular arrangement and the presence of an axial muscular pharynx is similar to conditions observed in other members of the Errantia too. Furthermore, nervous system and muscle staining as well as SEM and histological observations of different types of tubercles indicate a homology of the so called microtubercles, present in the long-bodied sphaerodorids, to the dorsal cirri of other Errantia. The macrotubercles seem to represent a sphaerodorid autapomorphy based on our investigations. Therefore, our results allow comparisons concerning morphological patterns between Sphaerodoridae and other Phyllodocida and constitute a starting point for further comparative investigations to reveal the evolution of the remarkable Sphaerodoridae.
\end{abstract}

Keywords: polychaetes, homology, CLSM, SEM, histology, muscular system, phyllodocida

\section{INTRODUCTION}

With more than 21,000 described species, the Annelida represent a quite specious and diverse taxon. Many of the well-established groups, often corresponding to the traditional families, are quite unknown, and their relationships, diversity, ecology, and biology have been scarcely investigated. One of these families is the remarkable Sphaerodoridae, a well-defined group of benthic marine worms characterized by the presence of spherical tubercles over their body surface arranged in longitudinal and transverse rows. They are an uncommon, relatively small group with around 110 species, generally found in deep sediments but also in other environments and depths (Capa et al., submitted). Knowledge concerning life cycle, developmental patterns and ecological claims like, e.g., food source, abiotic range of tolerance or knowledge concerning species annidation in members of this group is scarce so far. And while it is largely accepted that Sphaerodoridae is part of the phyllodocid radiation, its position within the group needs assessment (Pleijel and Dahlgren, 1998; Pleijel, 2001; Worsaae et al., 2005; Aguado et al.,
2007; Böggemann, 2009; Aguado and Bleidorn, 2010). This is mainly caused by missing homology statements of some of the key morphological characters comparable between sphaerodorids and other Phyllodocida (Fauchald and Rouse, 1997; Pleijel and Dahlgren, 1998) and the absence or scarce representation of members of this group in molecular phylogenies (Worsaae et al., 2005; Aguado et al., 2007; Böggemann, 2009; Aguado and Bleidorn, 2010; Weigert et al., 2014). Nevertheless, previous indications concerning potential sistergroups of Sphaerodoridae were represented by the families Syllidae (Ruderman, 1911; Glasby, 1993; Pleijel, 2001; Aguado and Rouse, 2006; Zrzavý et al., 2009), Phyllodocidae (Pleijel and Dahlgren, 1998; Kuper and Purschke, 2001) and Glyceriformia (Mileikovskii, 1967; Worsaae et al., 2005; Böggemann, 2009; Capa et al., submitted; see also Figure 1). However, detailed analyses supporting a reliable sistergroup relationship between Sphaerodoridae and other Phyllodocida are missing so far.

Since very early on, sphaerodorids were classified into two distinct groups according to their general body shape (e.g., Levinsen, 


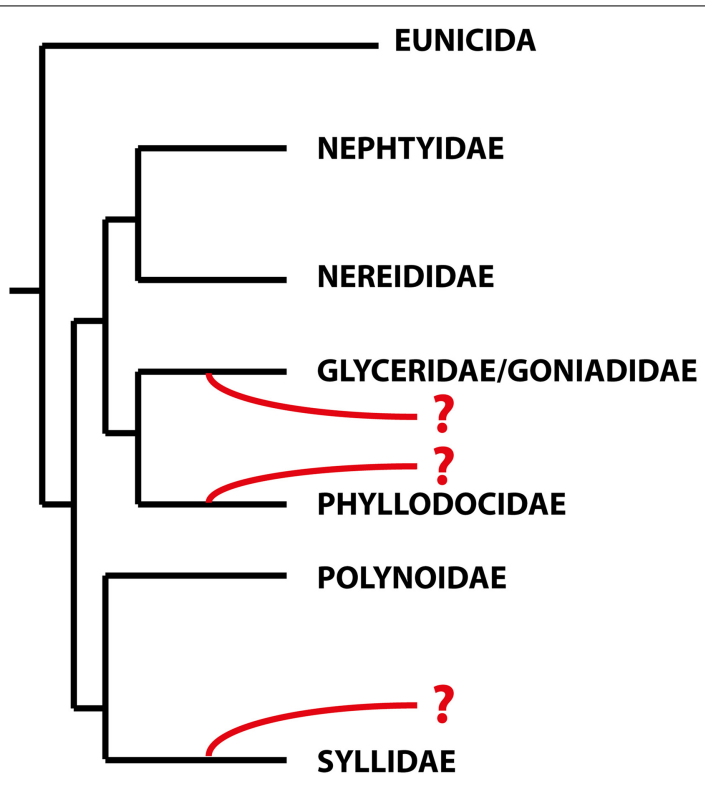

FIGURE 1 | Schematic topology of the relationships within the Errantia modified from Weigert et al. (2014). The phylogenetic positions of the Sphaerodoridae based on previous studies are indicated in red. Based on morphological data, sphaerodorids are either closely related to phyllodocids (Fauvel, 1911; Kuper and Purschke, 2001), whereas both molecular and morphological analyses support the glyceriformia as sister taxon (Worsaae et al., 2005; Böggemann, 2009; Capa et al., submitted). A possible close relationship between Sphaerodoridae and Syllidae is based on both morphological and molecular data (Claparède, 1863; Ruderman, 1911; Pleijel, 2001; Aguado and Rouse, 2006) and molecular analyses (Zrzavý et al., 2009).
1883; Fauvel, 1911; Chamberlin, 1919; Lützen, 1961; Pettibone, 1963; Fauchald, 1974). Most forms are small (less than $2 \mathrm{~mm}$ ) and have an ellipsoid body shape with a greatly convex dorsal surface (Figures 2C,D), but some species are characterized by having longer (up to $20 \mathrm{~mm}$ ) and slender bodies (Figures 2A,B), and only a slightly convex dorsal surface. Members of the genera Ephesiella (Chamberlin, 1919), Sphaerodorum (Ørsted, 1843) and Ephesiopsis (Hartman and Fauchald, 1971) fit into the second group of the so-called long-bodied sphaerodorids, whereas members of the other currently accepted genera could be considered (with some exceptions) as short-bodied sphaerodorids. The external morphology of the long-bodied sphaerodorids is largely homogenous among its members, with similar number, arrangement and type of epithelial tubercles, and a less conspicuous pharyngeal "proventricle" (Fauvel, 1911; Fauchald, 1974). Members of the three genera are only distinguished by the type of chaetae, ranging from simple in Sphaerodorum to compound, in Ephesiella, with Ephesiopsis presenting both types on each segment. Contrary, the short bodied sphaerodorids show a wide diversity in number and shape of epithelial tubercles, types of chaetae, and shape and relative size of head appendages (Figures 2C,D).

The terminology referring to the surface protuberances in Sphaerodoridae was unsystematically used until Fauchald (1974) proposed to classify them according to their size, shape, position
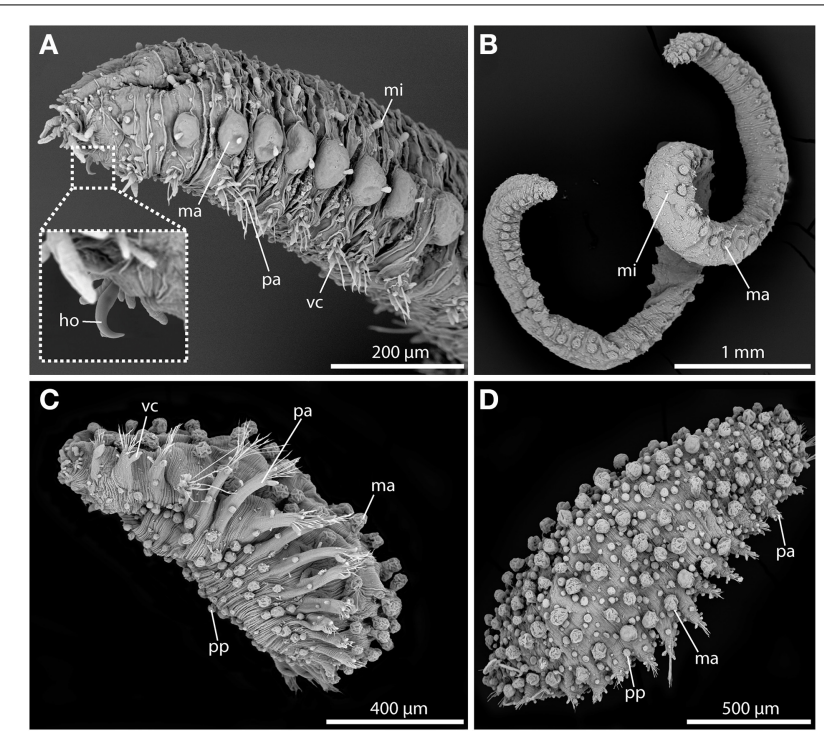

FIGURE 2 | SEM pictures showing long-bodied (A,B) and short-bodied Sphaerodoridae (C,D). (A) Lateral view of anterior end of Sphaerodorum flavum showing the prominent anterior chitinous hooks (ho) (see insert for detailed view), the digitiform microtubercles (mi), the pear-shaped ventral cirri (vc), and the spherical macrotubercles (ma) with terminal papillae. (B) Ephesiella sp. from Australia, with a single macro- (ma) and microtubercles (ma) on top of each parapodium on each body side, typical for long bodied sphaerodorids (anterior is up). (C) Sphaerodoridium sp. from Norway, in ventro-lateral view. Short bodied sphaerodorids exhibit macrotubercles (ma), papillae (pp) (in ventral surface and parapodia) and ventral cirrus (vc) (anterior is left). (D) Sphaerodoropsis cf. minuta in dorsal view with macrotubercles (ma) arranged in several longitudinal rows (anterior is right), with interspersed smaller papillae. ho, chitinous hook; ma, macrotubercle; mi, microtubercle; pa, parapodium; pp, papilla; vc, ventral cirrus.

and, in some cases, their hypothetical function in three different categories: macrotubercles (large dorsal tubercles, sessile or stalked, with or without terminal papillae; Figures 5A,C,D), microtubercles (dorsal small and digitiform tubercles surrounded by a basal collar; Figures 5A,B,D) and papillae (small, conical, spherical or hemispherical tubercles, on the body surface; Figures 6A-C).

Sphaerodorids, unlike most other Phyllodocida, do not show conspicuous external segmentation, and the epithelium is covered by a thick cuticle (Webster and Benedict, 1887; Ruderman, 1911; Capa et al., submitted), and lacking collagen fibers (Kuper and Purschke, 2001; Hausen, 2005), unlike most polychaetes.

Unlike sphaerodorids, most members of Phyllodocida possess distinct dorsal and ventral cirri associated to each parapodium, regardless if these are uniramous (e.g., Syllidae, some Glyceriformia and Phyllodocidae) or biramous (e.g., most Glyceriformia). Thus, members of Sphaerodoridae represent an atypical case since a distinct dorsal parapodial appendage is lacking. Therefore, it has been suggested that the lateral most row of macrotubercles present on Sphaerodoridae is homologous to the dorsal cirri of other Phyllodocida (Ruderman, 1911; Reimers, 1933; Fauchald, 1974), or that it could have been lost in a common ancestor of this group (Fauchald, 1974). Other parapodial protuberances in Sphaerodoridae have been described 
as parapodial lobes or parapodial papillae, and as ventral cirri (Claparède, 1863). Nevertheless, a sensory and/or glandular function has been tribute to all of them (Ruderman, 1911; Reimers, 1933; Capa et al., submitted), the understanding of their different nature and homology between taxa still needs investigations.

Besides differences within arrangement and types of epithelial tubercles, great variation is detectable also within the arrangement of body wall musculature. In general, muscular organization is shown to be a useful tool for understanding relationships among Annelida (Tzetlin and Filippova, 2005). Therefore, comparisons between sphaerodorids and syllids were done in the past and have already shown differences regarding number and the position of several body wall fibers (Filippova et al., 2010). Notably, variation between different members of Sphaerodoridae has also been found. Thus, some of the typical short-bodied forms (Sphaerodoropsis sp.) present longitudinal muscles forming four pairs of discrete bands along the whole body length, with the ventral-most pair being considerably larger than the rest (Reimers, 1933; Kuper and Purschke, 2001; Filippova et al., 2010). By contrast, the long-bodied forms, like Sphaerodorum flavum (Ørsted, 1843), apparently have only three pairs of longitudinal bundles and the dorsal and dorsolateral bundles being either fused or closely apposed (Ruderman, 1911; Kuper and Purschke, 2001). Small bands of transverse (or often called "circular") muscle fibers encircle the body between the epidermis and the longitudinal muscles in the studied sphaerodorids, except for a narrow gap in the mid-ventral line (Ruderman, 1911; Reimers, 1933; Kuper and Purschke, 2001; Filippova et al., 2010), apparently with an unusual position above the longitudinal fibers (Filippova et al., 2010).

Another remarkable character present in Annelida is the position and structure of the pharyngeal region. Based on several authors, members of Phyllodocida have a symmetrically developed axial pharynx with a strong muscular region that is often protrusible (e.g., Dales, 1962) and provided with papillae. Glycerids and goniadids (Glyceriformia) also bear chitinized structures such as macro- and/or micrognaths or chevrons (Böggemann, 2005). For sphaerodorids, the knowledge concerning pharyngeal morphology and taxon specific variation of the latter character is quite scarce. Nevertheless, for several short bodied species a syllid-like structure named "proventricle" is described (e.g., Filippova et al., 2010).

The proposed project aims to broaden the scant knowledge concerning sphaerodorid morphology and variation within the group, test (after assessment of similarity) if several morphological features used in traditional classifications are homologous and unveil the relationships of members of Sphaerodoridae and other Phyllodocida. For this purpose, integrative use of different microscopic and staining methods will be used, including scanning electron microscopy (SEM), histological staining (HES) and semi-thin sections, and immunohistochemistry with subsequent confocal laser scanning microscopy (CLSM). A description of used morphological features is summarized below.

\section{MATERIALS AND METHODS SAMPLING OF SPECIMENS}

The different species used in this study were obtained from scientific collections or sampled in the field. For further details concerning species identity, sampling location and used method of investigation, please see Table 1.

\section{LIGHT MICROSCOPY, PHOTOGRAPHY AND DISSECTION OF SPECIMENS}

Specimens were examined under a Leica MZ APO and a DM LBZ light and compound microscope, respectively. Photographs were taken with a Leica DFC 420 camera attached to a Leica MZ 16A light microscope and a DM 6000B compound microscope (Leica Microsystems, Wetzlar, Germany). Stacks of multi-focus shots were merged into a single photograph to improve resolution with Leica Application Suite v3.7 software (Leica Microsystems, Wetzlar, Germany). A longitudinal incision through the body wall along the ventrum, from the anterior to posterior segments allowed the broad examination of the internal morphology of specimens, especially the gut and musculature.

Methylene-blue staining was used to highlight glandular areas. Selected specimens were immersed in $70-80 \%$ ethanol for several minutes with some previously dissolved crystals of the compound.

\section{SCANNING ELECTRON MICROSCOPY}

Specimens were dehydrated in an ascending series of Hexamethyldisiloxane (HMDS) and then air dried. The prepared samples were mounted on holders and sputter-coated with gold (10 nm thickness). The micromorphology and topography were determined using a Philips FEI INSPECT (Hillsboro, Oregon, USA). The samples were observed with the Back Scattering Electron Detector (BSED) with a resolution at high vacuum of $4.0 \mathrm{~nm}$ at $30 \mathrm{kV}$.

\section{HISTOLOGY AND SEMI-THIN SECTIONS}

Specimens fixed in $4 \%$ formalin, were embedded in paraffin (Leica EG 1160), sectioned ( $4 \mu \mathrm{m}$, with a Leica RM 2255 microtome) and dried at $60^{\circ} \mathrm{C}$. Haematoxylin, Eythosine B and Saffron (HES) staining was performed in the automatic slide stainer Sakura Tissue-Tek@Prisma ${ }^{\mathrm{TM}}$. The slides were dried further in the instruments heat chamber, then de-paraffinized through several baths of Tissue Clear (Sakura, Alphen aan den Rijn, Netherlands) and rehydrated through descending grades of ethanol to water. Staining with haematoxylin was followed by bluing in water. Afterwards the slides were stained in erythrosine and rinsed in water for removal of excess dye. Subsequently, the samples were dehydrated through an ascending series of ethanol and stained in saffron (Chemi-Teknic as, Chroma), and rinsed in several baths of absolute ethanol and cleared in Tissue Clear before cover slipping in Sakura Tissue-Tek@Glas ${ }^{\mathrm{TM}}$ automatic coverslipper. The sections were dried overnight. Photographs were taken with a Leica DFC 420 camera attached to a DM 6000B compound microscope (Leica Microsystems, Wetzlar, Germany).

\section{IMMUNOHISTOCHEMISTRY AND CONFOCAL LASER SCANNING MICROSCOPY (CLSM)}

Whole-mount preparations as well as Vibratome sections were analyzed. Specimens were anesthetized for 5-10 $\mathrm{min}$ in a solution of $7 \% \mathrm{MgCl}_{2}$ in freshwater. Whole specimens were then fixed overnight in $4 \%$ paraformaldehyde in $0.1 \mathrm{M}$ phosphate buffered saline (PBS, pH 7.4). After several rinses in $0.1 \mathrm{M}$ PBS for at least 
Table 1 | Species identity, sample source and method of investigation shown for the specimens used within this investigation.

\begin{tabular}{|c|c|c|c|c|c|c|}
\hline Species & Locality & LM & MB & SEM & CLSM & HIST \\
\hline Ephesiella antarctica Mclntosh, 1885 & Antarctica (South Shetland Is.) & $x$ & & $X$ & & \\
\hline Ephesiella abyssorum (Hansen, 1879) & Norwegian Sea (several localities) & $x$ & $x$ & $x$ & & $x$ \\
\hline Ephesiella sp. & France (Britain) & $x$ & & & $x$ & \\
\hline Ephesiella sp. & Australia (Queensland) & $x$ & & $x$ & & \\
\hline Sphaerodoridium sp. & Norway (Nordland) & $x$ & & $x$ & & \\
\hline Sphaerodoropsis cf. minuta (Webster and Benedict, 1887) & Norwegian Sea (several localities) & $x$ & $x$ & $x$ & & $x$ \\
\hline Sphaerodoropsis cf. parva (Ehlers, 1913) & France (Atlantic) & $x$ & & $x$ & & \\
\hline Sphaerodoropsis sp. A & Australia (Queensland) & $x$ & & $x$ & $x$ & \\
\hline Sphaerodoropsis sp. B & Australia (Victoria) & $x$ & & $x$ & & \\
\hline Sphaerodoropsis sp. C & Australia (Victoria) & $x$ & & $x$ & & \\
\hline \multirow[t]{3}{*}{ Sphaerodorum flavum Ørsted, 1843} & France (Britain) & $x$ & & & $x$ & \\
\hline & Spain (Galicia) & $x$ & $x$ & $x$ & & \\
\hline & Norweagian Sea (several localities) & $x$ & $x$ & $x$ & & $x$ \\
\hline Sphaerodorum sp. & Canada (Northwest Territories) & $x$ & & $x$ & & \\
\hline Glycera tridactyla Schmarda, 1861 & France (Britain) & $x$ & & & $x$ & \\
\hline Eulalia clavigera (Audouin and Milne Edwards, 1833) & France (Nord-Pas-de-Calais) & $x$ & & & $x$ & \\
\hline Prosphaerosyllis sp. & Australia (Queensland) & $x$ & & & $x$ & \\
\hline
\end{tabular}

Note that for every species and method of investigation several specimens were occasionally examined. LM, light microscopy; MB, stained with methylene-blue; SEM, scanning electron microscopy; CLSM, confocal laser scanning microscopy; HIST, histological sections and HES staining.

$2 \mathrm{~h}$, specimens were stored in PBS containing $0.05 \% \mathrm{NaN}_{3}$ at $4^{\circ} \mathrm{C}$. For Vibratome sectioning, fixed specimens were rinsed in several changes of $0.1 \mathrm{M}$ PBS and embedded in a gelatine/albumin medium. The gelatin/albumin blocks were hardened overnight in $15 \%$ formalin in $0.1 \mathrm{M}$ PBS at $4^{\circ} \mathrm{C}$ and then cut with a VT1000S Vibratome (Leica Microsystems, Wetzlar, Germany) into 70-100 $\mu \mathrm{m}$ thin sections. The sections were washed in several changes of PBS and incubated and subsequently incubated as described for the F-actin and serotonin/tubulin staining.

\section{F-actin (= filamentous muscular actin) staining}

To stain muscle tissue, specimens were pre-incubated for $2 \times$ $60 \mathrm{~min}$ in $0.1 \mathrm{M} \mathrm{PBS}$ and subsequently incubated in a solution containing phalloidin-rhodamine $(5 \mu \mathrm{l}$ methanolic stock solution in $500 \mu \mathrm{l}$ PBS; Invitrogen, Darmstadt, Germany). Subsequently, specimens were dehydrated in an ascending isopropanol series, treated in Murray's clearing solution (benzyl alcohol plus benzyl benzoate, 1:2) and mounted between two coverslips in DPX (Sigma-Aldrich, St. Louis, USA).

Anti-serotonin (= 5-HT, neurotransmitter), anti-acetylated $\alpha$ tubulin (= basis of microtubules within cilia), and anti-tyrosinated $\alpha$-tubulin (= basis of microtubules within nerve sheaths) staining

Antibody staining was preceded by tissue permeabilization for $1 \mathrm{~h}$ in $0.1 \mathrm{M}$ PBS containing $0.1 \% \mathrm{NaN}_{3}$ and $0.1 \%$ Triton $\mathrm{X}-100$ (PTA), suited by incubation in block-PTA (6\% normal goat serum (Sigma-Aldrich, St. Louis, USA) in PTA) overnight. The primary antibodies, polyclonal rabbit anti-serotonin (INCSTAR, Stillwater, USA, dilution 1:500), monoclonal mouse anti-acetylated $\alpha$-tubulin (Sigma-Aldrich, St. Louis, USA, dilution 1:500), together with monoclonal mouse anti-tyrosinated $\alpha$-tubulin (Sigma-Aldrich, St. Louis, USA, dilution 1:500) were applied for $48-72 \mathrm{~h}$ in block-PTA. Afterwards, specimens were rinsed in block-PTA for $3 \times 2 \mathrm{~h}$ and incubated subsequently with secondary fluorochrome conjugated antibodies (goat antirabbit Alexa Fluor 488, Invitrogen, Carlsbad, USA, dilution 1:500) in block-PTA for 24-48 h. At last, the specimens were washed three times in $0.1 \mathrm{M}$ PBS (without $\mathrm{NaN}_{3}$ ). Subsequently, specimens were dehydrated in an ascending isopropanol series, treated in Murray's clearing solution (benzyl alcohol plus benzyl benzoate, 1:2) and mounted between two coverslips in DPX (SigmaAldrich, St. Louis, USA). For additional muscular staining, the last washing step of the antibody staining was performed including incubation in phalloidin-rhodamine as described for the F-actin staining. Negative controls were obtained by omitting the primary antibody in order to check for antibody specificity and yielded no fluorescence signal.

\section{Confocal microscopy and image processing}

Specimens were analyzed with the confocal laser-scanning microscope Leica TCS STED (Leica Microsystems, Wetzlar, Germany). Confocal image stacks were processed with Leica AS AF v2.3.5 (Leica Microsystems) and Imaris 6.3.1 (Bitplane AG, Zurich, Switzerland). Final panels were designed using Adobe (San Jose, USA) Photoshop CC and Illustrator CC.

\section{RESULTS}

\section{EPITHELIAL TUBERCLES}

\section{Macrotubercles}

The large tubercles in the long-bodied sphaerodorids are characterized by their spherical shape, the presence of a digitiform terminal papilla and its arrangement, one above each parapodium forming two longitudinal rows over the dorsum of the animals (Figures 2A,B). Macrotubercles are filled with fibrillar material that stains with methylene-blue, denoting its glandular content (observed in LM, not shown). An anti-serotonin 
staining reveals distinct serotonergic immunoreactivity within the terminal papillae, indicating prominent neuronal innervation of this region. A strong innervation within the vestigial structure is lacking. Furthermore, the surface of the macrotubercle is interspersed with distinct pores (Figures 3A,C,E). F-actin staining shows the presence of prominent sphincter-like muscles around theses pores (Figure 3B). Anti-serotonin staining exhibits serotonergic immunoreactivity in the pore area (Figure 3B ), and anti-acetylated $\alpha$ tubulin staining reveals the presence of cilia in close proximity to the pores (Figure 3D). Besides the described
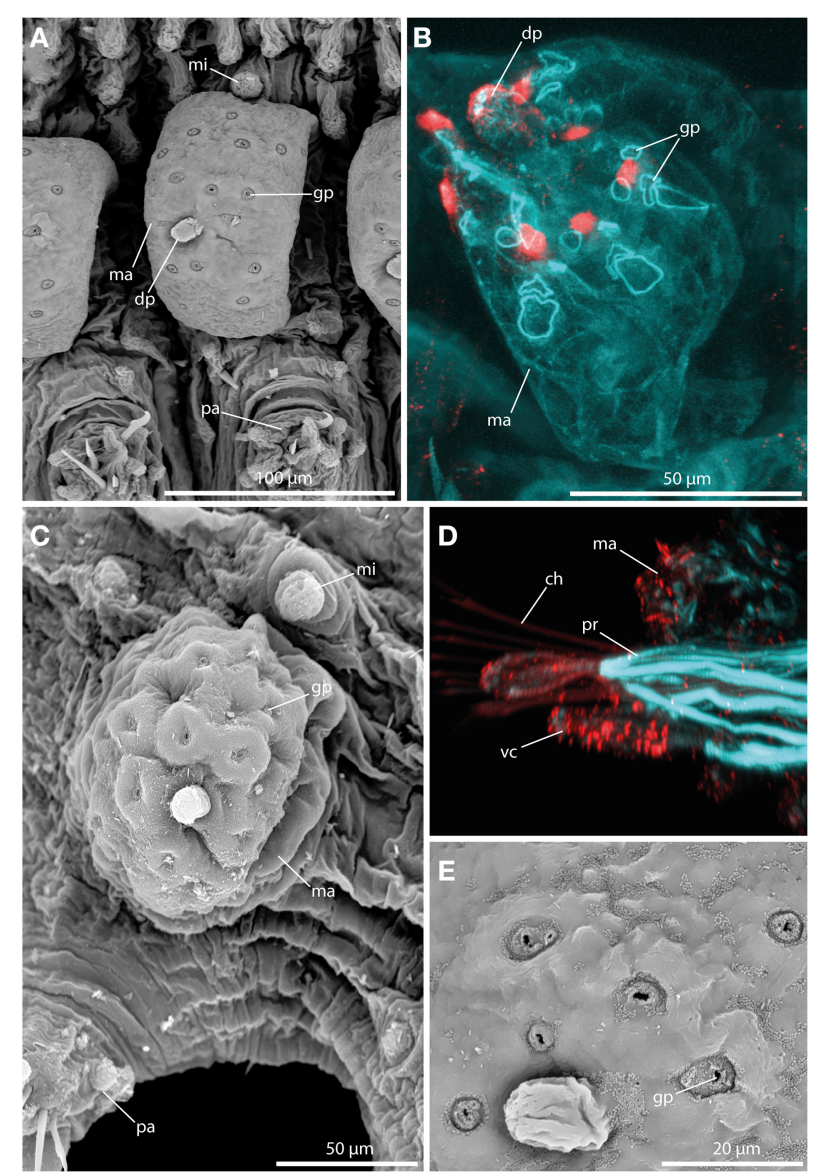

FIGURE 3 | The macrotubercle revealed by SEM (A,C,E) and CLSM (B,D). In (B) f-actin staining (blue) and serotonergic immunoreactivity (red) are shown. In (D) f-actin staining (blue) and tubulinergic immunoreactivity (red) are shown. (A) Macrotubercle (ma) of Sphaerodorum flavum showing a prominent distal papilla (dp), and distinct glandular pores (gp) on its surface. (B) Confocal maximum projection of the macrotubercle (ma) of Ephesiella sp. with sphincter-like muscles in close proximity to the glandular pores (gp). The glandular pores (gp) and the distal papilla (dp) show a prominent serotonergic immunoreactivity. (C) Ephesiella antarctica exhibiting a well-developed macrotubercle (ma), slighlty collapsed, possessing prominent glandular pores (gp), and a smooth microtubercle (mi). (D) Sphaerodoropsis cf. minuta showing prominent parapodial retractor muscles (pr) and ciliation with tubulinergic immunoreactivity covering the surface of the macrotubercle (ma) and ventral cirrus (vc). (E) Detailed of the pores within the macrotubercle of Sphaerodorum flavum. $\mathrm{dp}$, distal papilla; gp, glandular pore; ma, macrotubercle; mi, microtubercle; pa, parapodium; pr, parapodial retractor muscle; vc, ventral cirrus. immunoreactivity and f-actin staining of the glandular pores, the macrotubercle does not possess further prominent muscle fibers or neuronal innervation (see also Figure 9 for schematic overview).

Short-bodied sphaerodorids bear, in most cases, large tubercles over the dorsum but they have a different morphology in comparison to long-bodied forms and, regardless they are sessile or stalked, they lack the terminal papillae characteristic of the long-bodied forms (Figures 4A-D). Several species studied under SEM showed pores on the macrotubercles epithelium, smaller than the long bodied sphaerodorids and in most cases forming groups of three or four (Figures 4A,B). These tubercles also stained with methylene-blue and in some specimens in a random manner, indicating they may be able to arbitrarily discharge the glandular content (Figure 4C, see insert).

\section{Microtubercles}

Always present in long-bodied forms, these tubercles have also been attributed to two short-bodied Sphaerephesia species (Fauchald, 1972; Kudenov, 1987a), but they show different morphology, arrangement and most probably also different nature; so are considered herein as an autapomorphy for members of the long-bodied sphaerodorids. No pores were
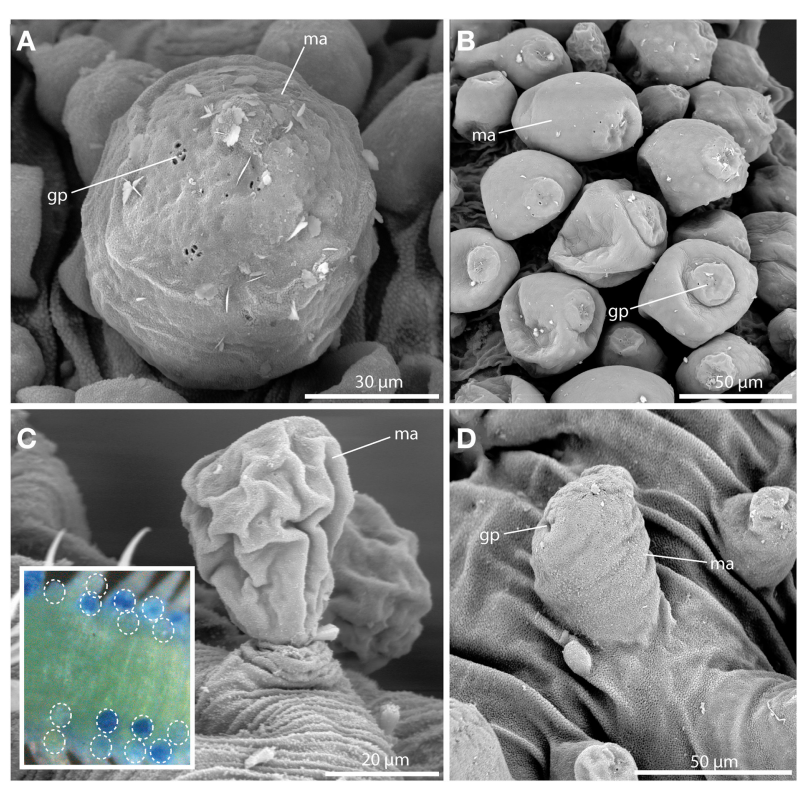

FIGURE 4 | The macrotubercle revealed by SEM (A-D) and

methylene-blue staining (insert in C). (A) Spherical macrotubercle (ma) in Sphaerodoropsis sp. A. from Australia showing glandular pores (gp) arranged in small groups. (B) Macrotubercles (ma) of Sphaerodoropsis sp. B. from Australia, are pear-shaped and glandular pores (gp) are concentrated at the distal end. (C) Sphaerodoropsis cf. minuta with stalked macrotubercles (ma). The insert shows the variable staining pattern of the macrotubercles with methylene-blue in Sphaerodoropsis philippi. The position of stained and unstained tubercles is marked by the white dotted circles. (D) In Sphaerodoropsis sp. C, from Australia, the macrotubercle (ma) is sessile, showing only few glandular pores (gp). gp, glandular pore; ma, macrotubercle. 
observed in their surface (Figures 5A-D), neither these structures stain with methylene-blue (not shown). Anti- $\alpha$-tubulin staining reveals the presence of a distinct neuronal innervation of the microtubercle, and strong immunoreactivity in the digitiform distal end (Figures 5E,F). F-actin staining shows longitudinal muscular fibers running through the whole microtubercle and absence of glandular sphincter muscles (Figure 5F). Additionally, the digitiform distal end is characterized by strong serotonergic immunoreactivity (see also Figure 9 for schematic overview), indicating strong neuronal innervation and sensory function.

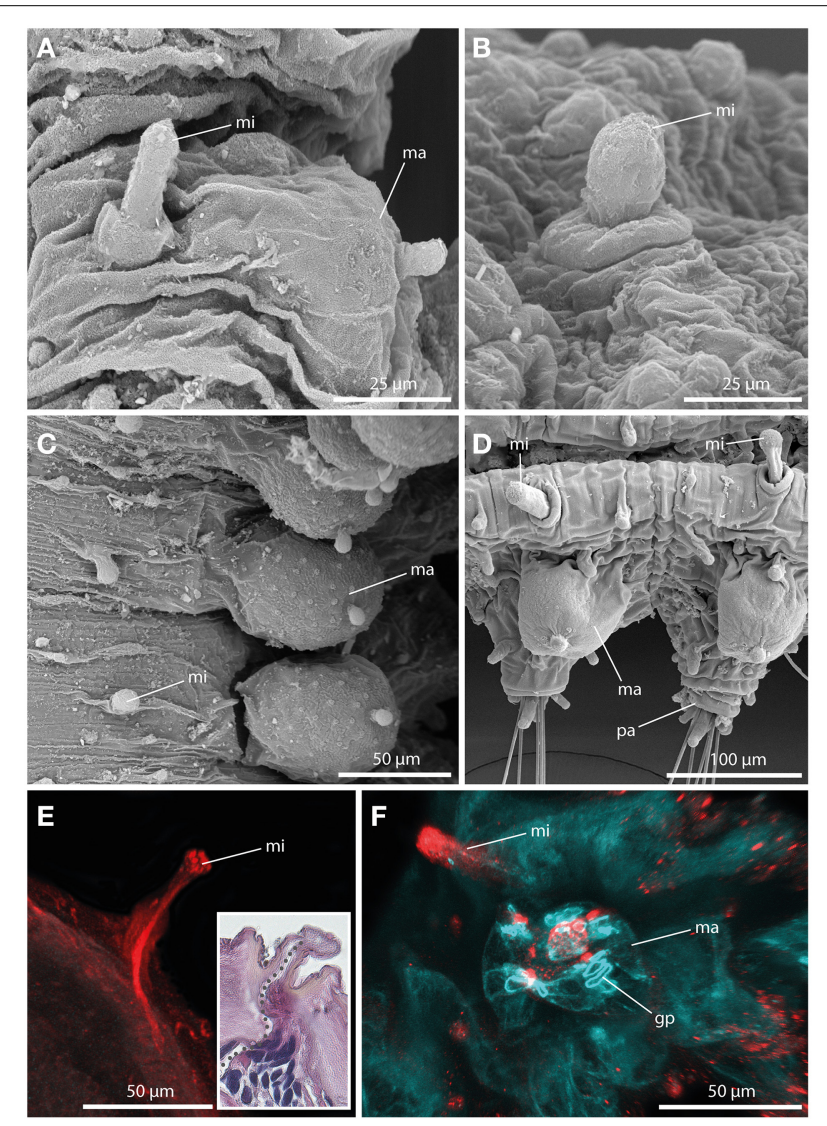

FIGURE 5 | The microtubercle revealed by SEM (A-D), CLSM (E,F), and histological HES staining (see insert in E). In (E) tubulinergic immunoreactivity (red) is shown. In (F) f-actin staining (blue) and serotonergic immunoreactivity (red) are shown. (A) Ephesiella abyssorum showing macro- (ma) and microtubercle (mi)with digitiform shape and a basal collar. (B) Detailed image of the microtubercle (mi) of Ephesiella antarctica with smooth surface. (C) Macro- (ma) and microtubercles (mi) of Sphaerodorum sp. from Canada, dorsal view (D) Parapodia of Ephesiella abyssorum microtubercles (mi) and the spherical macrotubercle (ma). (E) Confocal maximum projection of a cross-section of Ephesiella sp. from France showing the strong neuronal innervation of the microtubercle (mi) and the absence of ciliation. The insert shows a cross-section of a histological staining of the same region in Ephesiella abyssorum with the neuronal channel indicated by a gray dotted line. (F) Macro- (ma) and microtubercle (mi) of Ephesiella sp. from France with strong serotonergic immunoreactivity in the microtubercle (mi) and the absence of glandular pores (gp) within the latter structure. gp, glandular pore; ma, macrotubercle; mi, microtubercle; pa, parapodium.

\section{Papillae}

Papillae in Sphaerodoridae are smaller than the macrotubercles, and vary in size and shape (Figures 6A,C,E). These epithelial protuberances do not possess a digitiform terminal papillae and are generally described as sessile. Nevertheless, the different types of papillae exhibit strong neuronal and muscular innervation (Figures 6B,D,F), and a distinct ciliation (Figures 6C) indicating a sensory function. Furthermore, some papillae are known to have glandular pores (Figure 6A). However, methylene-blue staining solely results in a weak or lacking staining pattern indicating lacking glandular content.

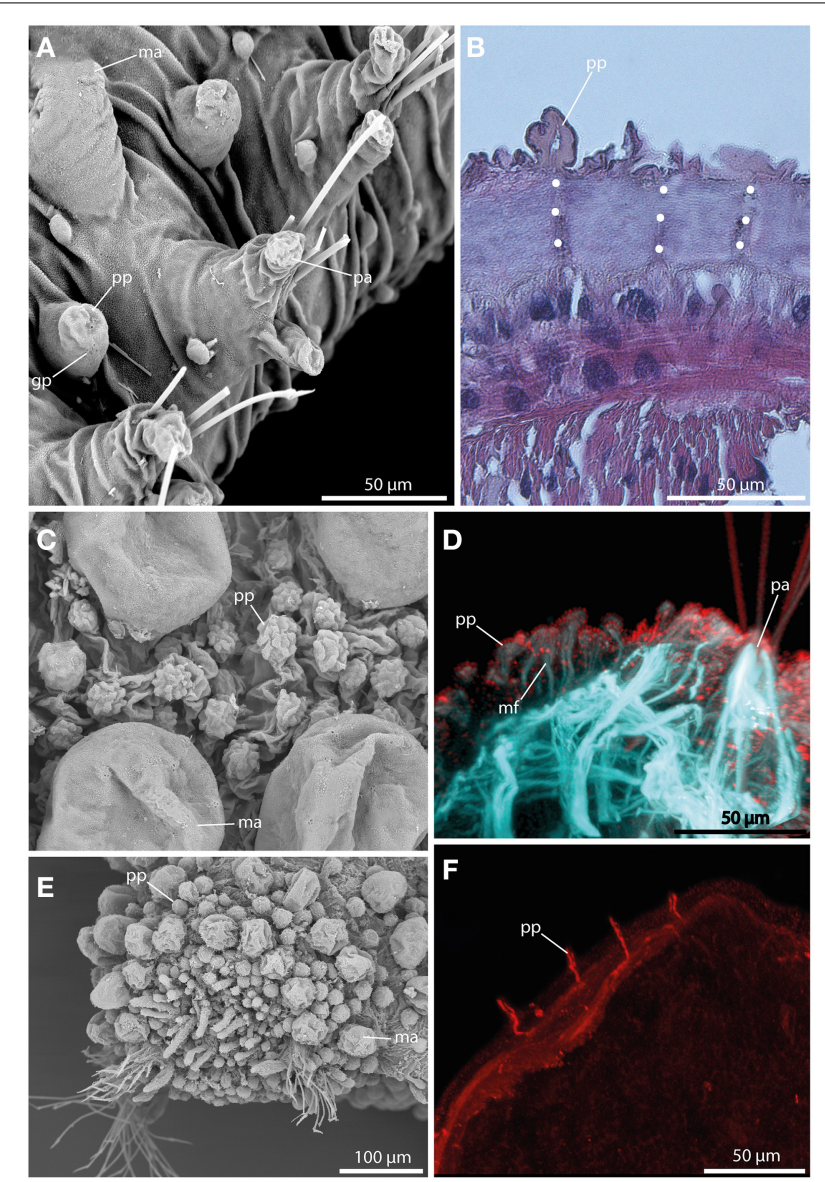

FIGURE 6 | The epithelial papillae revealed by SEM $(A, C, E)$, histological HES staining (B), and CLSM (D,F). In (D) f-actin staining (blue) and tubulinergic immunoreactivity (red) are shown. In (F) tubulinergic immunoreactivity (red) is shown. (A) Sphaerodoropsis sp. C, from Australia exhibits glandular pores (gp) within the papillae. (B) In Ephesiella abyssorum neuronal innervation (indicated by the white dotted line) of the papillae (pp) is detectable in histological sections. (C) Sphaerodoropsis cf. parva with papillae (pp) of various size and shape among macrotubercles. (D) Confocal maximum projection of a cross-section of Ephesiella sp. show distinct muscle fibers (mf) at the base of the papillae (pp) and ciliation on the surface. (E) Sphaerodoropsis cf. minuta exhibits different types of tubercles, including macrotubercles ( $\mathrm{ma}$ ) and papillae (pp) in addition to the head appendages (digitiform) at the anterior end. (F) Confocal maximum projection of a cross-section of Ephesiella sp., showing the strong neuronal innervation of the papillae (pp). gp, glandular pore; ma, macrotubercle; mf, muscle fiber; pa, parapodium; pp, papilla. 


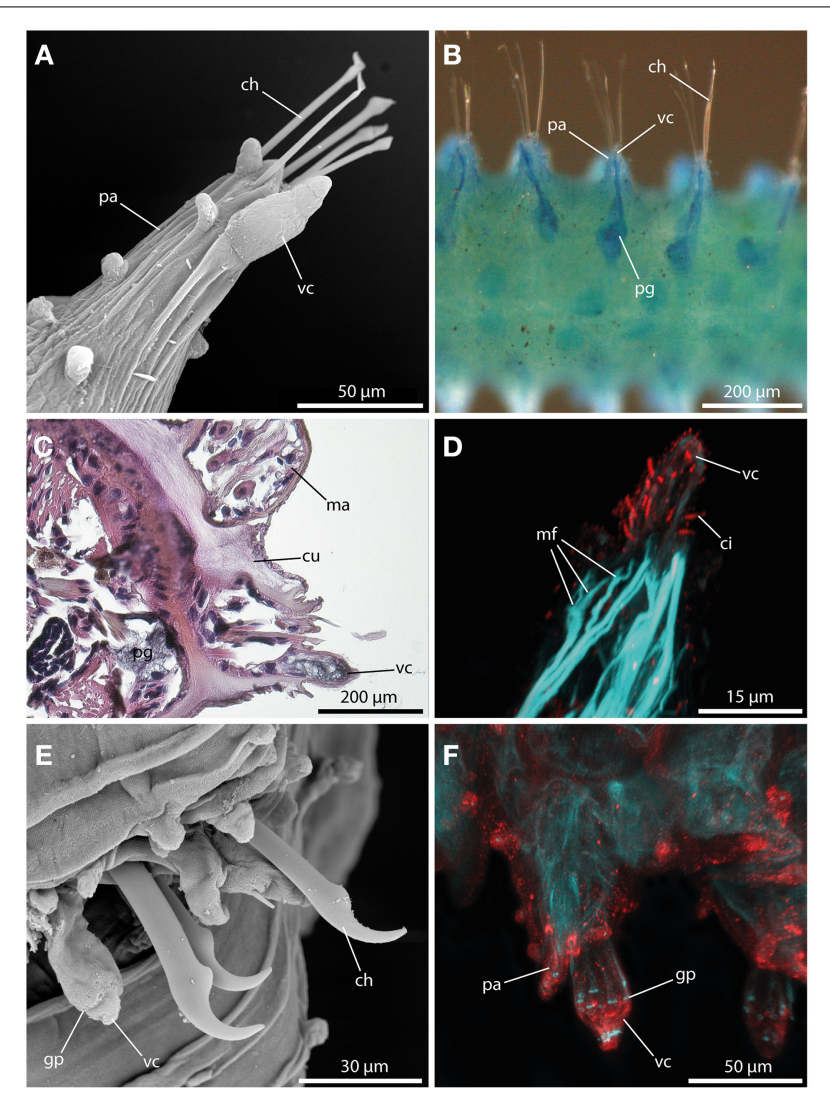

FIGURE 7 | The ventral cirrus revealed by SEM (A), methylene blue staining (B), histological HES staining (C), and CLSM (D,E). In (D) f-actin staining (blue) and tubulinergic immunoreactivity (red) are shown. In (E) f-actin staining (blue) and serotonergic immunoreactivity (red) are shown. (A) Ephesiella antarctica exhibits a pear-shaped ventral cirrus (vc) and several papillae on the parapodia (pa). (B) Ventral view of Ephesiella abyssorum reveals a parapodial gland $(\mathrm{pg})$ in close proximity and connected to the ventral cirrus (vc). (C) Cross-section of Ephesiella abyssorum., Note the glandular nature of the ventral cirrus (vc) and the close parapodial gland (pg) (dorsal is up) (D) Confocal maximum projection of the ventral cirrus (vc) of Sphaerodoropsis cf. minuta, showing prominent ciliation with tubulinergic immunoreactivity and muscle fibers ( $\mathrm{mf}$ ) innervating the ventral cirrus (vc). (E) Sphaerodorum flavum with glandular pores (gp) within the ventral cirrus (vc). (F) Confocal maximum projection of the parapodial region of Ephesiella sp. in dorsal view. The ventral cirrus (vc) shows strong serotonergic immunoreactivity and sphincter-like muscles in close proximity to the glandular pores (gp). ch, chaeta; ci, cilia; cu, cuticle; gp, glandular pore; ma, macrotubercle; mf, muscle fiber; pa, parapodium; pg, parapodial gland; vc, ventral cirrus.

\section{Ventral cirri}

A large digitiform or bottle-shaped tubercle commonly referred to as the ventral cirrus (Figures 7A,E,F) is located at the ventral edge of each parapodium in all sphaerodorids described to date. Methylene-blue staining and HES-staining show its glandular content and the presence of a ventral parapodial gland in close proximity to the ventral cirrus (Figures 7B,C). Furthermore, a connection between the gland and the cirrus is present (Figure 7B). Staining against acetylated- $\alpha$-tubulin reveals the presence of numerous cilia at the surface of the ventral cirrus (Figure 7D). Ventral cirri of most species studied (long and short-bodied forms) showed pores on the surface of this structure (Figures 7E,F) and the f-actin staining of the ventral cirrus exhibits sphincter-like musculature around the pores and a strong muscular innervation of the base (Figures 7D,F). The anti-serotonin staining possesses a prominent serotonergic immunoreactivity in close proximity to the pores and the apical tip (Figure 7F) (see also Figure 9 for schematic overview) indicating strong neuronal innervation and sensory areas.

\section{THE BODY WALL MUSCULATURE AND PARAPODIAL MUSCLE COMPLEX}

The sphaerodorids investigated herein represent two types of body wall muscle arrangements. Short-body forms (here Sphaerodoropsis cf. minuta (Webster and Benedict, 1887) exhibit six distinct longitudinal muscle bundles at the dorsal side (Figure 8A) and two prominent ventral longitudinal muscle bundles (Figure 8B). Furthermore, a consistent layer of transverse muscle fibers is present between the longitudinal bundles (Figures 8A,B; see also Figure 9A for schematic overview). Notably, an outer transverse layer lying above the longitudinal muscles is missing within the investigated species. Furthermore, neither the longitudinal nor the transverse muscle fibers reflect any kind of internal segmentation. In contrast, long-bodied forms (here Sphaerodorum flavum and Ephesiella sp.) exhibit a different pattern of body wall musculature. In these taxa, the longitudinal muscle bundles are arranged as two ventral, two dorsal and two distinct lateral bundles (Figures 8D-F). Additionally, the transverse fibers form a consistent dense outer layer located above the longitudinal bundles (Figures 8E,F; see also Figure 9B for schematic overview).

In terms of parapodial muscle fibers, both the short-bodied and the long-bodied forms investigated herein exhibit a similar pattern. Parapodia consist of distinct parapodial retractor muscles and prominent chaetal flexor muscles forming the $\mathrm{V}$-shaped parapodial cone (Figure 8C). Additionally, distinct acicula retractor muscles leading from the base of the aciculum toward the body margin are present in both groups (Figures 8A,B).

\section{THE PHARYNX}

Fixed sphaerodorids sometimes show a slightly everted pharynx provided with at least terminal papillae (Figure 10A). Short-body forms exhibit a thickened muscular axial bulbous (Figure 10F). This structure is often visible through the body wall with light microscopy as different in arrangement of fibers to the rest of the gut. Contrary, long-bodied forms show an often coiled pharynx anteriorly that progressively enlarges or is diminished in size but has no clear apparent distinction from the rest of the gut (see this most likely artificially everted structure in Figure 10A, and in a dissected specimen in Figure 8B). The axial pharynx is quite prominent in the elongated sphaerodorids [e.g., shown here for Ephesiella sp. (Figure 10B) and Sphaerodorum flavum (Figure 10C)], whereas the stout forms solely possess a small muscular bulb (shown for Sphaerodoropsis cf. minuta; Figure 10F). In sagittal and cross sections, distinct radial muscle fibers are visible (Figures 10C-E,G). Forming the outer part of the muscular pharynx, the radial fibers run from the pharyngeal 

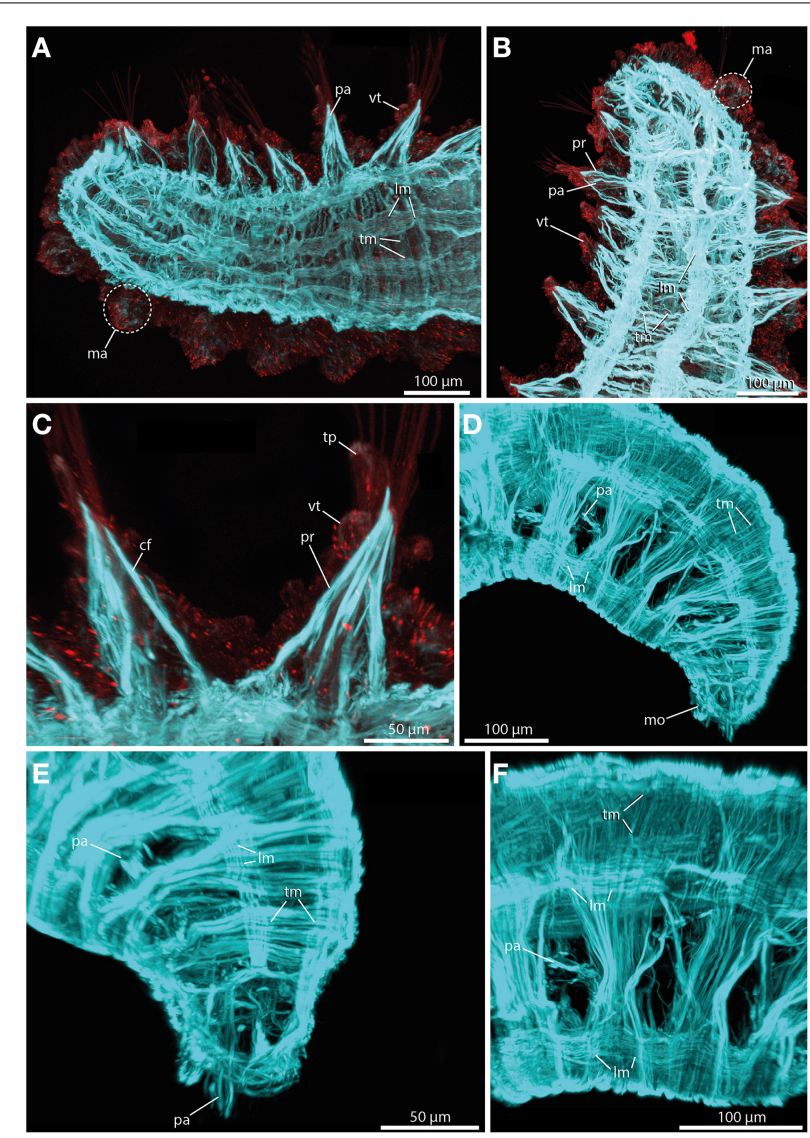

FIGURE 8 | Confocal maximum projections of f-actin pattern (blue) and tubulinergic (anti-acetylated- $\alpha$-tubulin) immunoreactivity (red) in Sphaerodoropsis minuta (A-C) and Sphaerodorum flavum (D-F). Anterior is left in $(\mathbf{A}, \mathbf{C}, \mathbf{F})$, up in (B), and down in (D) and (E). (A) In dorsal view, distinct longitudinal muscle fibers $(\mathrm{Im})$ arranged in bundles and prominent transverse muscle fibers (tm) are visible. (B) In ventral view, short bodied sphaerodorids exhibit prominent ventral longitudinal muscle fibers (Im) arranged in two distinct bundles. (C) The parapodium in ventral view possesses well-developed chaetal flexor muscles (cf) and parapodial retractor muscles (pr). Furthermore, the ventral cirrus (vc) and the termina papilla (tp) show ciliation and exhibit tubulinergic immunoreactivity. (D) Long bodied sphaerodorids represent well-developed ventral and dorsal longitudinal muscle fibers $(\mathrm{Im})$ and a dense meshwork of transverse muscle fibers (tm) forming an outer muscle layer. (E) The transverse muscle fibers form an outer muscle layer. Solely the region of the parapodia (pa) is left out. (F) A lateral view of the midbody regions reveals the presence of longitudinal muscle fibers $(\mathrm{Im})$ within one ventral, one latero-dorsal and one dorsal-most bundle. cf, chaetal flexor muscle; Im, longitudinal muscle fiber; ma, macrotubercle; mo, mouth opening; pa, parapodium; pr, parapodial retractor muscle; tm, transverse muscle fiber; tp, terminal papilla; vc, ventral cirrus.

lumen toward the outer surface of the pharynx (Figures 10C-E). In Sphaerodorum flavum, the radial fibers seem much denser in the pharyngeal bulbous, whereas the anterior buccal cavity only possesses an irregular meshwork of muscle bundles (Figure 10C). At least within the investigated long bodied taxa, the buccal cavity exhibits distinct longitudinal muscle fibers. The pharyngeal lumen of the posterior part is framed by an additional prominent muscular layer formed by distinct bundles of fibers (Figure 10D).
A

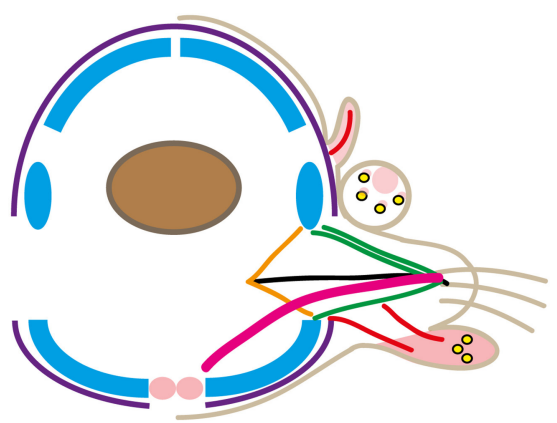

B

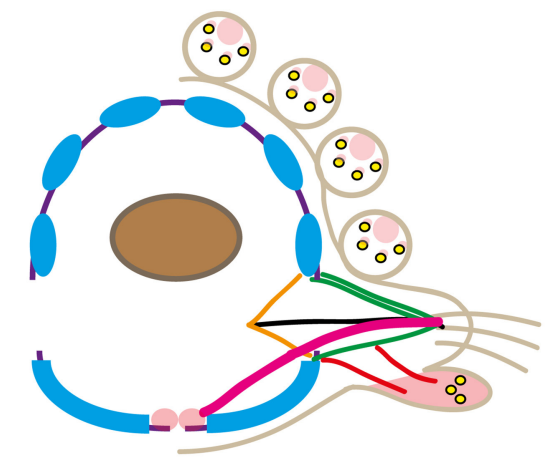

\section{LM \\ TM \\ IN \\ MF}

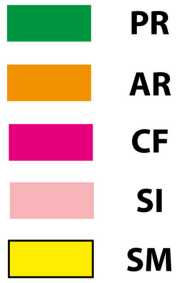

FIGURE 9 | Schematic representation of muscular patterns and serotonergic immunoreactivity within cross-sections long bodied ( $A$ ) and short bodied (B) sphaerodorids. Dorsal is up in all images. Main muscle fibers and serotonergic immunoreactivity are color-coded (see legend), ar, acicular retractor; cf, chaetal flexor; in, intestine; Im, longitudinal musculature; mf, muscle fiber innervating the ventral tubercle; pr, parapodial retractor muscle; si, serotonergic immunoreactivity; sm, glandular sphincter-like muscle; tm, transverse muscle fiber.

In both, the elongated and stout forms, the radial muscle fibers are arranged in distinct rows surrounding the whole pharynx (Figures 10F,G).

\section{MUSCULAR AND NEURONAL PATTERNS WITHIN BODY APPENDAGES OF POTENTIAL SISTER TAXA}

Due to the fact that the sistergroup of Sphaerodoridae is discussed controversially (Figure 1), we investigated representative species out of the candidates postulated in the past, namely Glyceridae (Glyceriformia), Phyllodocidae and Syllidae (see Ruderman, 1911; Glasby, 1993; Pleijel and Dahlgren, 1998; Kuper and Purschke, 2001; Pleijel, 2001; Worsaae et al., 2005; Aguado and Rouse, 2006; Böggemann, 2009; Zrzavý et al., 2009; Capa et al., submitted). To provide important and so far 


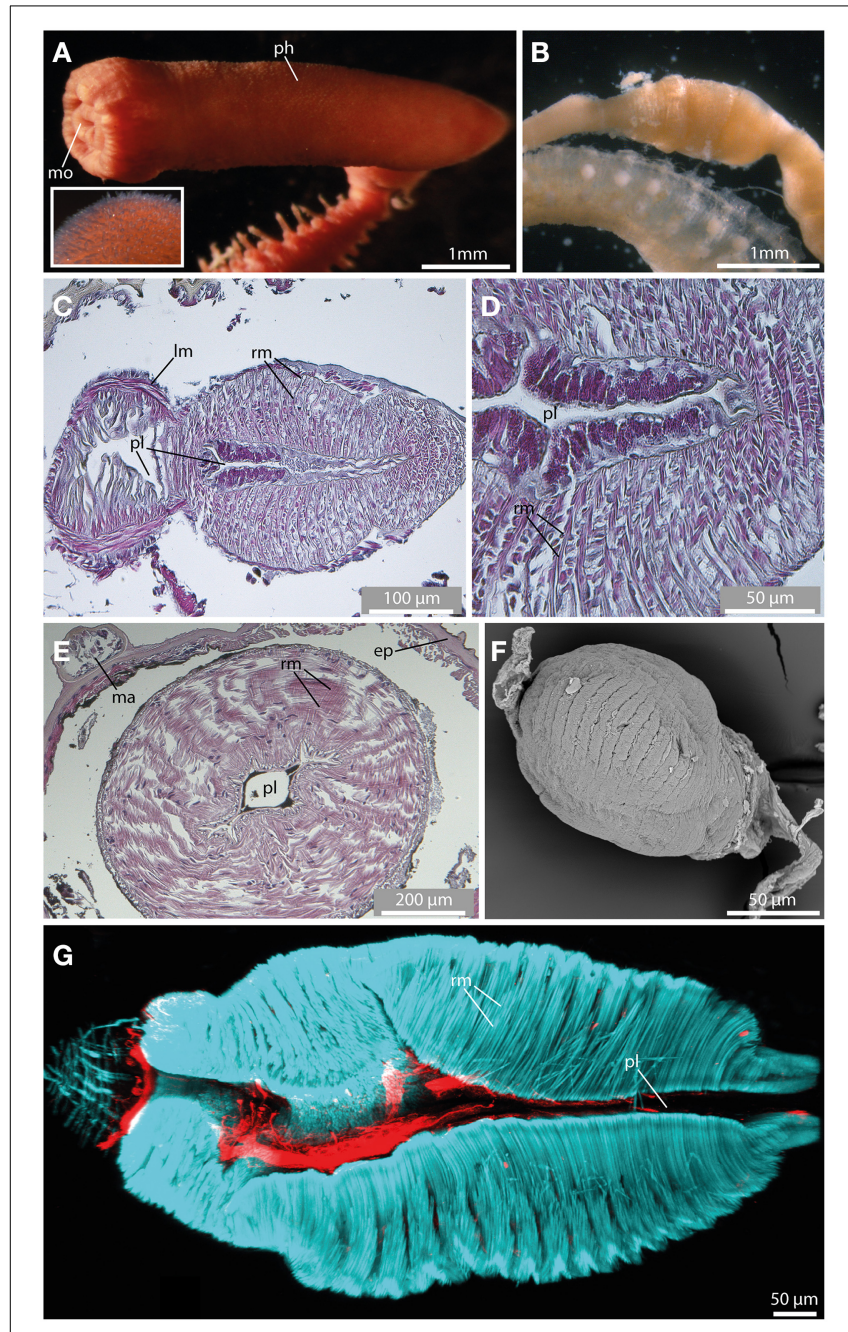

FIGURE 10 | The pharynx revealed by light microscopy $(A, B)$, histological HES staining (C-E), SEM (F), and CLSM (G). In (G) f-actin staining (blue) and serotonergic immunoreactivity (red) are shown. (A) The everted pharynx of Ephesiella antarctica exhibits an elbow-like shape, and possesses prominent papillae (see insert). (B) Ephesiella sp. with removed pharynx. Notably, a pharyngeal bulb is visible. (C) Sagittal section of the muscular pharynx in Sphaerodorum flavum, anterior is left. Note radial muscle fibers (rm) surrounding the pharyngeal lumen (pl). (D) Detailed picture showing a sagittal section of the muscular pharynx in Sphaerodorum flavum. (E) Cross-section of the pharynx in Ephesiella sp. showing prominent radial muscle fibers ( $\mathrm{rm}$ ) leading from the pharyngeal lumen (pl) toward the pharyngeal surface. (F) Sphaerodoropsis cf. minuta exhibits a similar muscular pharynx like observed in Ephesiella and Sphaerodorum. (G) A sagittal section of the muscular pharynx of Sphaerodorum flavum reveals well-developed radial muscle fibers (rm). ep, epidermis; Im, longitudinal muscle fiber; ma, macrotubercle; mo, mouth opening; ph, pharynx; pl, pharyngeal lumen; rm, radial muscle fiber.

missing comparable morphological characters, we investigated the myoanatomy and serotonergic nervous system of Glycera tridactyla (Glyceridae), Eulalia clavigera (Phyllodocidae) and Prosphaerosyllis sp. (Syllidae).

In Glycera tridactyla (Schmarda, 1861) (Glyceriformia) the body wall musculature comprises two prominent ventral and two dorsal longitudinal muscle bundles forming an inner muscle layer (Figure 11A). Notably, the longitudinal bundles are not fused. The outer transversal muscle fibers are situated mainly at the dorsal side forming a less dense outer muscle layer. The transverse muscle fibers do not form a continuous layer (Figure 11A). Instead, the transverse muscle fibers are also involved into the formation of the outer surface of the parapodium, but with focus on main muscular patterns this fact is not included herein. Furthermore, the parapodia are biramous and represent two sets of prominent parapodial retractor muscle fibers forming the V-shaped parapodial outer cone. Additionally, distinct acicula retractor muscles run from the base of the aciculum toward the lateral body margin and chaetal flexor muscles leading from the chaetal tip toward the medio-ventral region are exhibited (Figure 11A). Further on, Glycera has distinct dorsal and ventral cirri. Both types of cirri possess a well-defined muscular innervation (mainly at the basal part) and distinct serotonergic immunoreactivity (Figure 11A).

In Eulalia clavigera (Phyllodocidae) the body wall musculature is also comprised of two prominent ventral and two dorsal longitudinal muscle bundles forming the inner layer of the body wall muscle complex (Figure 11B). Like described for Glycera, the longitudinal bundles are not fused. Additionally, a median longitudinal muscle bundle is present, running along dorsally of the inner side of the ventral nerve cord. The outer transverse muscle fibers are similar to the conditions described for glycerids as well. Thus, they are situated mainly dorsally forming a less dense outer muscle layer. The transverse muscle fibers do not form a continuous layer (Figure 11B). In Eulalia, the parapodia are uniramous and represent one set of distinct parapodial retractor muscle fibers forming the outer parapodial cone, well-developed acicular retractor muscles and chaetal flexor muscles leading from the chaetae toward the medio-ventral region (Figure 11B). In Eulalia, the dorsal and ventral cirri are well developed with the dorsal cirri forming paddle-like appendages. Both types of cirri possess a well-defined muscular innervation (mainly at the basal part) and distinct serotonergic immunoreactivity (Figure 11B).

Muscular patterns and serotonergic immunoreactivity in Prosphaerosyllis sp. (Syllidae) is comparable to the conditions described for Glycera and Eulalia. Thus, the body wall musculature is represented by two prominent ventral and two dorsal longitudinal muscle bundles forming an inner muscle layer (Figure 11C). The longitudinal bundles are not fused and a median muscle bundle is present as well. The outer transverse muscle fibers are situated mainly at the dorsal body forming a less dense outer muscle layer. The transverse muscle fibers do not form a continuous layer (Figure 11C). The parapodia in Syllidae are uniramous and gain prominent parapodial retractor muscle fibers representing the outer part of the parapodial cone. Additionally, distinct acicular retractor muscles connecting the aciculum with the body wall musculature and prominent chaetal flexor muscles leading from the chaetal tip toward the median muscle bundle are possessed (Figure 11C). Again distinct dorsal and ventral cirri are present. Both types of cirri bear a well-defined muscular innervation (at basal and apical parts) and distinct serotonergic immunoreactivity (Figure 11C). 

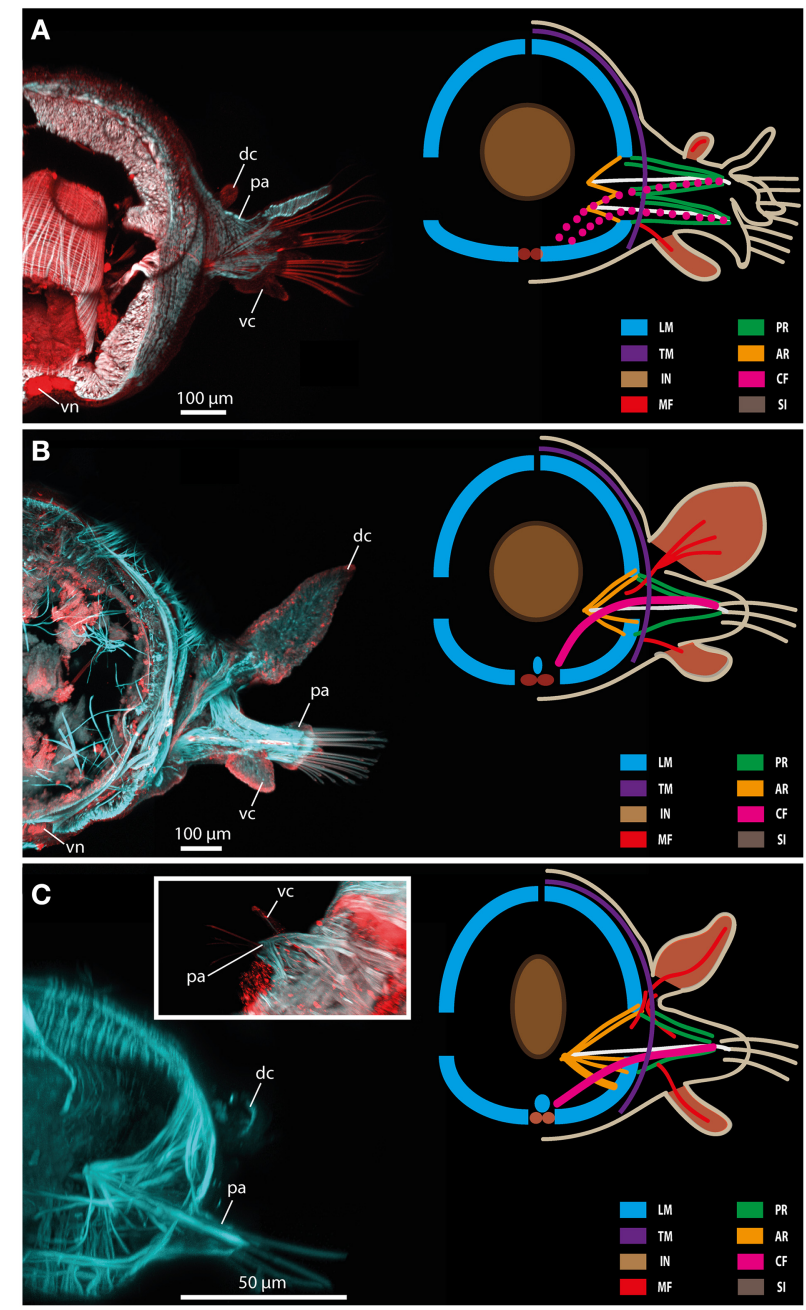

FIGURE 11 | Confocal maximum projections (left) and schematic representation of muscular patterns and serotonergic immunoreactivity in Glycera tridactyla (A), Eulalia clavigera (B), and Prosphaerosyllis sp. (C). Within the confocal maximum projections, f-actin fibers (blue) and serotonergic immunoreactivity (red) are shown. In the schematic drawing, major muscle fibers and serotonergic immunoreactivity are color-coded (see included legend). The insert in (C) shows a ventral view of the parapodial region exhibiting the ventral cirrus (vc). AR, acicular retractor muscle; $C F$, chaetal flexor muscle; dc, dorsal cirrus; IN, intestine; LM, longitudinal muscle fiber; MF, muscle fibers innervating the cirri; pa, parapodium; PR, parapodial retractor muscle; SI, serotonergic immunoreactivity; TM, transverse muscle fibers; vc, ventral cirrus; vn, ventral nerve mass.

\section{DISCUSSION}

Different morphological methods alone provide a limited picture of organ systems and their complex morphological characters. In this paper, we combine various standard morphological methods, like light microscopy, SEM and histological staining, and immunohistochemistry with subsequent CLSM to understand the morphology, structure and function of selected features and to establish homology statements within Sphaerodoridae and between them and other members of Phyllodocida. For the first time, a detailed comparison between a range of sphaerodorids, including long and short bodied forms is presented. Furthermore, we provide necessary and so far missing data concerning myoanatomical and neuronal patterns of the previously considered potential sphaerodorid sister taxa Glyceriformia, Phyllodocidae, and Syllidae.

\section{SPHAERODORID TUBERCLES AND HOMOLOGY STATEMENTS}

A remarkable feature of the Sphaerodoridae is the presence of various types of tubercles. In earlier studies it has been speculated that these structures could be either refer to the ovaries (Ørsted, 1844), respiratory organs (Johnston, 1845), secretory glands (Claparède, 1863), sensory glands (Kölliker, 1864; SaintJoseph, 1894) or a combination of the latter two (Ruderman, 1911; Capa et al., submitted). Herein, we show that the socalled macrotubercles exhibit a thinner cuticle compared to the rest of the body and numerous pores on their surface (see also Claparède, 1863). The glandular internal structure and the presence of neuronal and muscular innervation around the pores support their secretory function (as in Ruderman, 1911; Capa et al., submitted) while the strong neuronal innervation of the terminal papilla and the presence of outer cilia indicates an additional sensory role (as in Ruderman, 1911; Filippova et al., 2010; Capa et al., submitted).

Macrotubercles of the species studied showed evident pores, with some ciliation, and they are filled with glandular content regardless their different external morphology (with or without terminal papillae or stalks). All of these structures also presented a neuronal innervation restricted to the distal end and muscle fibers present at the base of the structure and surrounding the pores (sphincter muscles) on its surface. They are therefore here considered as homologous structures among the Sphaerodoridae. Even though members of Eurysyllis (Ehlers, 1864) (Syllidae) are described to exhibit four longitudinal rows of spherical tubercles provided with pores (San Martín, 2003) and members of Goniadopsis (Fauvel, 1928) (Goniadidae) are described with up to four more or less distinct flattened tubercles occurring on each side of the dorsum of anterior mid-body segments (Böggemann, 2005), their nature and also the ultrastructure are unknown so far and could represent adaptations to their lifestyles without a common origin.

Earlier studies have postulated homology of the sphaerodorid macrotubercles with the dorsal cirri of other polychaetes (Ruderman, 1911; Reimers, 1933), a hypothesis that is here refuted. Instead, some evidences point to the microtubercles present in the long-bodied sphaerodorids as homologous structures to dorsal cirri in other polychaetes. There are only one pair per segment, located dorsally to the parapodia, they seem to lack glandular content and pores, and instead they are strongly innervated. These characteristics are similar to the dorsal cirri of other taxa. However, e.g., in Syllidae, some dorsal cirri are described to contain glandular content as well (San Martín, 2003). The muscular arrangement of microtubercles is reduced, but this has also shown to be the case in other polychaetes (e.g., Filippova et al., 2010). Thus, our data indicate a homology of the microtubercles found in sphaerodorids and the dorsal cirri known for other Errantia. If long-bodied forms are basal in the sphaerodorid radiation, the absence of comparable 
structures in the investigated short-bodied sphaerodorids would indicate a secondary loss. Besides their presence in the longbodied sphaerodorids, microtubercles have also been reported in two species of Sphaerephesia (Fauchald, 1972, 1974; Kudenov, 1987a) but their morphology shows differences with the microtubercles of long-bodied forms, and are considered herein just papillae.

According the remaining minor tubercles, known as papillae, their neuronal and muscular innervation, and the presence of distinct ciliation indicate a sensory function as described for the other tubercle types. Nevertheless, glandular pores as described for the other types are only exhibited within some papillae, but negative methylene-blue staining indicates absence of glandular content within these protuberances. Flabelligeridae (SalazarVallejo et al., 2008) and some Syllidae (Sphaerosyllis Claparède, 1863; Prosphaerosyllis San Martín, 1984, 2003, San Martín et al., 2008) exhibit prominent papillae at the body surface as well, but function and fine-structure are unknown so far. Therefore, homology statements are hardly possible.

According to the similar muscular and neuronal innervation of the ventral cirri, which is comparable to conditions observed within the potential sister taxa and the presence in members of most Phyllodocida, our data support a homology of ventral cirri in sphaerodorids and the ventral cirri in the remaining Phyllodocida. Furthermore, other syllids also exhibit distinct pores within the ventral cirri, and distinct parapodial glands with pores at the parapodial surface are known for e.g., Syllidae, Nephtyidae and Pisionidae as well (Clark, 1955; Akesson, 1961; Russell, 1991; San Martín, 2003; San Martín et al., 2008).

\section{MYOANATOMY AND PHYLOGENETIC IMPLICATIONS}

In concordance with a previous CLSM-based study from Filippova et al. (2010) dealing with muscular patterns of the short bodied sphaerodorid Sphaerodoropsis sp., and the histological investigations of Reimers (1933) done for Sphaerodoropsis sp. and Sphaerodoropsis baltica (Reimers, 1933), our data support the presence of eight distinct longitudinal muscle bundles forming two prominent ventral and three pairs of dorsal longitudinal bundles in short-bodied sphaerodorids, forming the inner layer of the body wall musculature (Reimers, 1933; Kuper and Purschke, 2001; Filippova et al., 2010). Interestingly, the herein investigated long-bodied sphaerodorids (Ephesiella and Sphaerodorum) exhibit two prominent ventral longitudinal muscle bundles and only two pairs of dorsal longitudinal muscle bundles, as indicated by Ruderman (1911) and Kuper and Purschke (2001). These muscular bands are composed of large flattened cells lying in single rows and with the nuclei located on the distal part facing the coelomic cavity (Kuper and Purschke, 2001; Tzetlin and Filippova, 2005).

Elongated sphaerodorids like, e.g., Sphaerodorum and Ephesiella, possess transverse muscle fibers covering mainly dorsal and lateral body parts between the epidermis and the longitudinal muscles, similar to other Phyllodocida examined. Notably, a ventro-median gap within the transverse muscle layer is present (see also Ruderman, 1911; Reimers, 1933; Kuper and Purschke, 2001). In short-bodied sphaerodorids the muscular arrangement of the transverse fibers varies drastically. In these taxa, the transverse muscle layer is represented by few distinct bands located in each segment and these are situated between the longitudinal ones (see also Filippova et al., 2010). An outer transverse muscle layer encircling the longitudinal muscle bundles is absent. Additionally, prominent bracing muscle fibers are described for Sphaerodoropsis (Filippova et al., 2010). A homology of the transverse muscle fibers, and the transverse/circular muscle fibers in the elongated sphaerodorids and other annelids has to be verified.

Presence of prominent longitudinal bundles and dorsal transverse fibers is reported for most phyllodocid annelids (Tzetlin and Filippova, 2005; Purschke and Müller, 2006). Thus, four distinct longitudinal bundles are present in most Errantia (Tzetlin and Filippova, 2005), and the presence of two additional dorsal longitudinal muscle fibers in long-bodied Sphaerodoridae and four additional fibers in short-bodied forms has to be assumed as a secondary condition. A dorsal outer muscle layer of transverse muscle fibers is also known for Hesionidae, Nereidididae, Syllidae, Myzostomida and Phyllodocidae (Tzetlin and Filippova, 2005; Purschke and Müller, 2006; Filippova et al., 2010; Helm et al., 2013). Being also present in taxa outside the phyllodocid radiation, like e.g., in most Eunicida and Sedentaria, and members of the Amphinomidae and Sipuncula (see Weigert et al., 2014 for phylogenetic details, Gustafson, 1930; Wanninger et al., 2005; Purschke and Müller, 2006; Filippova et al., 2010) a plesiomorphic condition has to be assumed for the presence of transverse muscle fibers. Therefore, the arrangement of longitudinal and transverse muscle fibers in long-bodied sphaerodorids is similar to the conditions known for most annelids, and thus has to be regarded as an ancestral character. A division of the dorsalmost longitudinal bundles into smaller bundles as described for the long-bodied sphaerodorids is also known for several members of the Errantia, e.g., Syllidae, Polynoidae, Chrysopetalidae, Aphroditidae, and Myzostomida (Tzetlin and Filippova, 2005; Purschke and Müller, 2006; Helm et al., 2013). Due to the high variability concerning the arrangement of longitudinal muscle bundles in different taxa, usability of this character for evolutionary questions remains unclear (see also Tzetlin and Filippova, 2005). Nevertheless, distinct bracing muscles, like described for short bodied sphaerodorids, are known for most Phyllodocida as well (Mettam, 1971; Tzetlin and Filippova, 2005). The specific arrangement of transverse fibers in between the longitudinal muscle bundles, like described for the short bodied Sphaerodoridae, is hardly visible in other annelid families so far. The only comparable arrangement of transverse muscle fibers is described for Lobatocerebridae (Rieger, 1991) and Spionidae (Filippova et al., 2005). However, detailed investigations of the latter data suggest convergent origin of the described patterns. Furthermore, herein presented data indicate a secondary loss of "true" outer transverse fibers in short bodied sphaerodorids, and thus give another hint for these clade as being derived within the Sphaerodoridae. According to the parapodial arrangement and muscular innervation, sphaerodorids exhibit a pattern which is known for other phyllodocid polychaetes as well. Sphaerodoridae typically possess uniramous parapodia supported by a single straight aciculum. Similar parapodial muscle patterns showing prominent sets of protractor and flexor muscles can be found within the biramous 
Glyceridae, Aphroditidae, and Nereididae, and are shown herein for the uniramous phyllodocids and syllids, and the putatively errant Myzostomida as well (Storch, 1968; Tzetlin and Filippova, 2005; Helm et al., 2013). Notably, within Glyceriformia, several taxa are uniramous as well and others bear both uni- and biramous conditions (e.g., Storch, 1968). Thus, the plesiomorphic parapodial muscle pattern supports an phyllodocid ancestry of the Sphaerodoridae, too. Due to similar muscular arrangements within all possible sistergroups, a statement concerning a sphaerodorid ancestry based on muscular patterns is hardly possible.

\section{THE MUSCULAR PHARYNX}

Besides the presence of tubercles covering the whole animal and the remarkable myoanatomy, another notable feature of sphaerodorids is the presence of an axial muscular pharynx, comparable to others found in other Phyllodocida (Rouse and Fauchald, 1997; Pleijel, 2001; Tzetlin and Purschke, 2005; Filippova et al., 2010). Although often termed as "proventricle" (a structure typical for Syllidae) (Ruderman, 1911; Reimers, 1933; Rouse and Fauchald, 1997; Pleijel and Dahlgren, 1998; Pleijel, 2001; Worsaae et al., 2005; Aguado and Rouse, 2006), based on detailed investigations (Filippova et al., 2010), a homology of the sphaerodorid bulbous muscular pharyngeal structure and the syllid proventricle has to be neglected. In sphaerodorids the muscular pharynx does not exhibit the structures typical for the pharynxes in Syllidae, such as a division into an eversible, straw-like, muscular pharyngeal tube followed by a non-eversible sucking bulb-like proventricle with highly specialized musculature (see Tzetlin and Purschke, 2005 and references therein). Thus, the term "proventricle" should be avoided in this group. Nevertheless, our data indicate the presence of a proventriclelike muscular axial pharynx in long-bodied Sphaerodoridae for the first time, as it has been considered as absent in the past (Fauvel, 1911). Superficial differences between short and long bodied forms indicate that the pharynx present in Ephesiella and Sphaerodorum is divergent to the fully developed barrel-shaped structure present in short bodied sphaerodorids. Nevertheless, the less developed proventricle-like structure in long bodied forms is embedded in a well-developed axial pharynx with thickened circular muscles if sectioned. Some authors also have proposed that this pharynx is eversible (Ruderman, 1911; Reimers, 1933; Pettibone, 1963, 1982; Fauchald, 1974, 1977; Rouse and Fauchald, 1997; Wilson, 2000) and that it is provided with terminal papillae (Rathke, 1843; Fauvel, 1911; Ruderman, 1911; Wilson, 2000), two characters which are supported by our data as well.

\section{PROSTOMIAL APPENDAGES IN SPHAERODORIDAE}

According to the literature available, comparisons of the sphaerodorid prostomial appendages with the appendices found in other Phyllodocida are hardly possible. Investigations of the neuronal innervation of the anterior appendages are missing so far (Orrhage, 1990; Orrhage and Müller, 2005) and misinterpretations of neuronal characters lead to confusions in the past (Glasby, 1993; Aguado and Rouse, 2006; Reuscher and Fiege, 2011). As shown herein, most sphaerodorids investigated so far bear two pairs of anterior prostomial appendages, and a single dorsal-most appendage which often differs in shape and size, but there are some species described with three pairs of lateral appendages and a single dorsal one. Based on several recent publications the ventral-most pair of appendages is named palps, the dorsal pair lateral antennae, and the unpaired appendage is called median antennae (Rouse and Fauchald, 1997; Pleijel and Dahlgren, 1998; Wilson, 2000; Pleijel, 2001; Worsaae et al., 2005; Aguado and Rouse, 2006; Böggemann, 2009; Filippova et al., 2010; Magalhães et al., 2011; Moreira and Parapar, 2011; Reuscher and Fiege, 2011; Moreira, 2012), and the extra dorsal most pair has often been referred to as annteniform papillae. Compared with other errant annelids, this naming seems plausible (Aguado and Rouse, 2006). However, glycerids and goniadids show a different morphology of the anterior end (Orrhage, 1999). Based on the recent data, a homology statement of the prostomial appendages in sphaerodorids compared to structures in other members of the Errantia is not possible. Thus, more investigations are needed dealing with the neuronal innervation and ultrastructural details of these remarkable structures.

\section{SPHAERODORID SISTERGROUP RELATIONSHIPS}

Mainly due to the development of the pharynx forming an ellipsoid muscular structure, called "proventricle" (Ruderman, 1911; Glasby, 1993; Pleijel, 2001; Aguado and Rouse, 2006), a close relationship of syllids and sphaerodorids was early suggested by various authors. Besides this prominent character, the presence of uniramous parapodia, compound chaetae, the absence of parapodial branchiae in most species and a scarcely developed circulatory system (Claparède, 1863), in combination with some DNA sequence data (Zrzavý et al., 2009) were found as indications that supported such close relationship. Nevertheless, other molecular studies (Aguado et al., 2007; Capa et al., submitted) and differences in the arrangement of pharyngeal muscle fibers (Filippova et al., 2010 and herein) did not reach same conclusions.

Other shared similarities like the muscular axial pharynx exhibiting terminal papillae (Fauvel, 1911), occurrence of protonephridia with distinct solenocytes, and a well-developed vascular system (Kuper and Purschke, 2001) and mitochondrial sequences (Capa et al., submitted), were suggested as evidences for a sistergroup relationship of Sphaerodoridae and Phyllodocidae. Nevertheless, analyses of morphological data (Pleijel and Dahlgren, 1998) neglected a closer relationship of both taxa.

Additionally, Sphaerodoridae and Glyceriformia have been suggested as being sistergroups due to analyzes dealing with molecular data (Böggemann, 2009; Capa et al., submitted) or combined morphological and molecular datasets (Worsaae et al., 2005). Although, earlier discussions concerning a potential relationship have taken place (Rathke, 1843; Grube, 1850), only some similarities on the larval development have been reported so far (Mileikovskii, 1967).

Based on our analyses, the question concerning a sphaerodorid ancestry cannot be unequivocally solved. Due to our myoanatomical investigations, all three possible sister 
taxa provide a similar set and arrangement of body wall and parapodial muscles (see Figure 11). Furthermore, the myoanatomy and serotonergic innervation of the cirri is comparable between all three groups. Recent molecular analyses including a comprehensive group of sphaerodorids and other Phyllodocida representatives indicated sistergroup relationship of Sphaerodoridae and Goniadidae, but only weakly supported (Capa et al., submitted). There are no morphological features that could be considered as the synapomorphies supporting this close relationship. Both sphaerodorids and goniadids have a different general aspect, body wall musculature, head morphology and pharynx development (Orrhage, 1999; Böggemann, 2005). Sphaerodorids share some superficial similarities with phyllodocids such as the presence of reduced head appendages, presence of an eversible pharynx with papillae, provided with strong circular muscles and the occurrence of protonephridia with distinct solenocytes (Fauvel, 1911; Kuper and Purschke, 2001), but there are also sound differences between members of these two groups. Further developmental studies are needed to limit the field of potential sistergroups and to solve the question concerning a sphaerodorid ancestry. Nevertheless, we provide fundamental morphological insights into myoanatomical and neuronal features of sphaerodorids and the three possible sistergroups important for further comparative analyses.

\section{CONCLUSIONS}

We provide important new details into the sphaerodorid morphology, as well as into the myoanatomy and neuroanatomy of the three potential sistergroups, giving further support for a phyllodocid ancestry of these enigmatic worms. Thus, the pattern of body wall and parapodial musculature and the presence of an axial muscular pharynx is similar to conditions observed for other members of the Phyllodocida. Nevertheless, the presence of a thick cuticle and the epithelial tubercles arranged in rows, represent sphaerodorid autapomorphies. Further on, neuronal and muscular patterns as well as detailed external and histological observations of the tubercles indicate a homology of microtubercles present in long-bodied sphaerodorids and dorsal cirri in other Phyllodocida. Additionally, the appendices known as ventral cirri in sphaerodorids and those cirri of other Phyllodocida appear to be homologous as well. Macrotubercles of at least the taxa examined seem homologous, but it will be interesting to assess the sphaerodorid relationships and establish the character polarization of macrotubercles, considering taxa described lacking these large tubercles (Kudenov, 1987b; Sardá-Borrroy, 1987). Notably, long bodied sphaerodorids seem to represent several features shared with other Phyllodocida (presence of microtubercles as reduced dorsal cirri, muscular pharynx not developed as a bulbous, barrel-shaped structure and transverse fibers covering the longitudinal bands). Recent molecular investigations aiming to assess Sphaerodorid relationships with DNA sequence data (Capa et al., submitted) do not preclude such a hypothesis. Results indicate that Sphaerodorum and Ephesiella are derived within the Sphaerodorid topology. Further molecular and morphological investigations and developmental studies are necessary to illuminate the evolution of Sphaerodoridae and to solve the question of a possible sphaerodorid ancestry.

\section{AUTHOR CONTRIBUTIONS}

The authors declare that they contributed equally to the manuscript. Both authors designed the study, performed the experiments, and wrote and corrected the manuscript.

\section{ACKNOWLEDGMENTS}

We acknowledge support from the German Research Foundation (DFG), ForBio Research School in Biosystematics and Leipzig University within the program of Open Access Publishing. We thank Christoph Bleidorn (Leipzig University), Maria Teresa Aguado and Helena Wiklund for helpful comments on an earlier version of the manuscript. Additionally, we thank Martin Schlegel for providing materials and facilities for the CLSM work (Leipzig University) and Ingunn Nervik (NTNU) for help in the histology lab. The staff of the Station Biologique de Roscoff (France) is gratefully acknowledged for help with the collection of specimens and for providing laboratory space; some specimens were also kindly loaned from Australian Museum and Museum Victoria (Australia) and Muséum National d'Histoire Naturelle, Paris. Most SEMs were taken during MC visits to the Museo Nacional de Ciencias Naturales de Madrid with travel grant provided by the European Commission Taxonomic Initiative SYNTHESYS (ES-TAF-3520, ES-TAF-2839).

\section{REFERENCES}

Aguado, M. T., and Bleidorn, C. (2010). Conflicting signal within a single gene confounds syllid phylogeny (Syllidae, Annelida). Mol. Phylogenet. Evol. 55, 1128-1138. doi: 10.1016/j.ympev.2010.01.012

Aguado, M. T., Nygren, A., and Siddall, M. E. (2007). Phylogeny of Syllidae (Polychaeta) based on combined molecular analysis of nuclear and mitochondrial genes. Cladistics 23, 552-564. doi: 10.1111/j.1096-0031.2007.00163.x

Aguado, M. T., and Rouse, G. W. (2006). First record of Sphaerodoridae (Phyllodocida: Annelida) from hydrothermal vents. Zootaxa 1383, 1-21.

Akesson, B. (1961). On the histological differentiation of the larvae of Pisione remota (Pisionidae, Polychaeta). Acta Zool. Stockholm 42, 177-225. doi: 10.1111/j.1463-6395.1961.tb00063.x

Audouin, J. V., and Milne Edwards, H. (1833). Classification des Annélides et description de celles qui habitent les côtes de la France. Ann. Sci. Nat. Paris 29, 195-269.

Böggemann, M. (2005). Revision of the Goniadidae (Annelida: Polychaeta). Abh Naturwissenschaftlichen Ver. Hamburg Neue Folgen 39, 1-354.

Böggemann, M. (2009). Polychaetes (Annelida) of the abyssal SE Atlantic. Org. Divers. Evol. 9, 251-428. doi: 10.1016/j.ode.2009.10.001

Chamberlin, R. V. (1919). The Annelida Polychaeta. Mem. Mus. Comp. Zool. Harv. Coll. 48, 1-514.

Claparède, R. E. (1863). Beobachtungen über Anatomie und Entwicklungsgeschichte wirbelloser Thiere an der Küste von Normandie angestellt. Leipzig: Wilhelm Engelmann. doi: 10.5962/bhl.title.10030

Clark, R. B. (1955). The posterior lobes of the brain of Nephtys and the mucus glands of the prostomium. Q. J. Microsc. Sci. 3, 545-565.

Dales, R. P. (1962). The polychaete stomodeum and the inter-relationships of the families of Polychaeta. Proc. Zool. Soc. Lond. 139, 389-428. doi: 10.1111/j.14697998.1962.tb01837.x

Ehlers, E. (1864). Die Borstenwürmer (Annelida Chaetopoda) nach systematischen und anatomischen Untersuchungen dargestellt, Vol. 1. Leipzig: Wilhelm Engelmann. doi: 10.5962/bhl.title.2081

Ehlers, E. (1913). "Die Polychaeten-Sammlungen der deutschen SüdpolarExpedition, 1901-1903," in Deutsche Südpolar-Expedition 1901-1903 im Auftrage des Reichsamtes des Innern Herausgegeben, Vol. 13, ed E. von Drygalski, (Berlin: Georg Reimer), 397-598.

Fauchald, K. (1972). Benthic polychaetous annelids from deep water off western Mexico and adjacent areas in the Eastern Pacific Ocean. Allan Hancock Monogr Mar. Biol. 7, 1-575. 
Fauchald, K. (1974). Sphaerodoridae (Polychaeta: Errantia) from world-wide areas. J. Nat. Hist. 8, 257-289. doi: 10.1080/00222937400770241

Fauchald, K. (1977). The Polychaete worms, Definitions and Keys to the Orders, Families and Genera, Science Series. Los Angeles, CA: Natural History Museum of Los Angeles County.

Fauchald, K., and Rouse, G. W. (1997). Polychaete Systematics: past and present. Zool. Scr. 26, 71-138. doi: 10.1111/j.1463-6409.1997.tb00411.x

Fauvel, P. (1911). Campagne Arctique de 1907. Annélides Polychètes. Bruxelles: Duc d'Orleans.

Fauvel, P. (1928). Annélides Polychètes nouvelles de l'Inde. I. Bull. Mus. Hist. Nat. Paris 34, 90-96.

Filippova, A., Purschke, G., Tzetlin, A. B., and Müller, M. C. M. (2005). Reconstruction of the musculature of Magelona cf. mirabilis (Magelonidae) and Prionospio cirrifera (Spionidae)(Polychaeta, Annelida) by phalloidin labeling and cLSM. Zoomorphology 124, 1-8. doi: 10.1007/s00435-004-0106-7

Filippova, A., Purschke, G., Tzetlin, A. B., and Müller, M. C. M. (2010). Musculature in polychaetes: comparison of Myrianida prolifera (Syllidae) and Sphaerodoropsis sp. (Sphaerodoridae). Invertebr. Biol. 129, 184-198. doi: $10.1111 /$ j.1744-7410.2010.00191.x

Glasby, C. J. (1993). Family revision and cladistic analysis of the Nereidoidea (Polychaeta: Phyllodocida). Invertebr. Taxon. 7, 1551-1573. doi: 10.1071/IT9931551

Grube, A. E. (1850). Die Familien der Anneliden. Arch. Naturgeschichte Berlin 16, 249-364.

Gustafson, G. (1930). Anatomische studien über die Polychäten-familien Amphinomidae und Euphrosynidae. Zoologiska Bidrag Uppsala Bd. 12, 305-471.

Hansen, G. A. (1879). Annelider fra den norske Nordhavsexpedition i 1876. Nyt Magazin Naturvidenskaberne Christiania 24, 1-17.

Hartman, O., and Fauchald, K. (1971). Deep-water benthic polychaetous annelids off New England to Bermuda and other North Atlantic Areas. Part II. Allan Hancock Monogr. Mar. Biol. 6, 1-327.

Hausen, H. (2005). "Chaetae and chaetogenesis in polychaetes (Annelida)," in Morphology, Molecules, Evolution and Phylogeny in Polychaeta and Related Taxa, Vol. 535/536, Hydrobiologia, eds G. Purschke and T. Bartolomaeus, 199-225.

Helm, C., Weigert, A., Mayer, G., and Bleidorn, C. (2013). Myoanatomy of Myzostoma cirriferum (Annelida, Myzostomida): implications for the evolution of the Myzostomid body plan. J. Morphol. 274, 456-466. doi: 10.1002/jmor.20107

Johnston, G. (1845). Miscellanea Zoologica. Classe Annelides; order Errantes; family Nereides. Ann. Mag. Nat. Hist. 16, 4-10. doi: 10.1080/037454809494524

Kölliker, A. (1864). Kurzer Bericht über einige vergleichend anatomische Untersuchungen. Würzbg. Naturwiss. Z. 5.

Kudenov, J. D. (1987a). Five New Species of Sphaerodoridae (Annelida: Polychaeta) from the Gulf of Mexico. P. Biol. Soc. Wash. 100, 927-935.

Kudenov, J. D. (1987b). Four species of Sphaerodoridae (Annelida: Polychaeta) including one new genus and three new species from Alaska. P. Biol. Soc. Wash. $100,917-926$.

Kuper, M., and Purschke, G. (2001). The excretory organs in Sphaerodorum flavum (Phyllodocida, Sphaerodoridae) - a rare case of co-occurrence of protonephridia, coelom and blood vascular system in Annelida. Zoomorphology 120,191-203. doi: 10.1007/s004350000035

Levinsen, G. M. R. (1883). Systematisk-geografisk oversigt over de nordiske Annulata, Gehyrea, Chaetognathi og Balanoglossi. Videnskabelige Meddelelser fra Dansk naturhistorisk Forening, 1-354.

Lützen, J. (1961). Sur une nouvelle espèce de Polychète Sphaerodoridium commensalis. n. gen., n. spec. (Polychaeta Errantia, famille des Sphaerodoridae), vivant en commensal de Terebellides stroemi Sars. Cah. Biol. Mar. 2, 409-416.

Magalhães, W. F., Bailey-Brock, J. H., and Barrett, B. M. (2011). A new species of Sphaerephesia (Polychaeta: Sphaerodoridae) from Mamala Bay, south shore of Oahu, Hawaii. Zootaxa 2903, 39-47.

McIntosh, W. C. (1885). Report on the Annelida Polychaeta collected by H. M. S. Challenger during the years 1873-1876. Report on the Scientific Results of the Voyage of H.M.S. Challenger during the years 1872-76, Ser. Zoology 12, 1-554.

Mettam, C. (1971). Functional design and evolution of the polychaete Aphrodite aculeata. J. Zool. Lond. 163, 489-514. doi: 10.1111/j.1469-7998.1971.tb04546.x

Mileikovskii, S. A. (1967). Larval development of polychaetes of the family Sphaerodoridae and some considerations of its systematics. Dokl. Bioi. Sci. (Transl.) 177, 851-854.
Moreira, J. (2012). “Familia Sphaerodoridae Malmgren, 1867," in Fauna Ibérica (ed by M. A. Ramos et al.) Vol. 36, Annelida Polychaeta III, eds J. Parapar, C. Alós, J. Núñez, J. Moreira, E. López, F. Aguirrezabalaga, C. Besteiro, and A. Martínez, (Madrid: Museo Nacional de Ciencias Naturales, CSIC), 16-43.

Moreira, J., and Parapar, J. (2011). Sphaerodoridae (Annelida: Polychaeta) from the Bellingshausen Sea (Antarctica) with the description of two new species. Polar Biol. 34, 193-204. doi: 10.1007/s00300-010-0869-x

Orrhage, L. (1990). On the microanatomy of the supraoesophageal ganglion of some amphinomids (Polychaeta Errantia), with further discussion of the innervation and homologues of the polychaete palps. Acta Zool. Stockholm 71, 45-59. doi: 10.1111/j.1463-6395.1990.tb01180.x

Orrhage, L. (1999). On the morphological value of the glycerid-goniadid prostomium and its appendages (Polychaeta). Acta Zool. Stockholm 80, 251-264. doi: 10.1046/j.1463-6395.1999.00025.x

Orrhage, L., and Müller, M. C. M. (2005). Morphology of the nervous system of Polychaeta (Annelida). Hydrobiologia 535/536, 79-111. doi: 10.1007/s10750004-4375-4

Ørsted, A. S. (1843). Annulatorum danicorum conspectus. Volume Fasc. 1 Maricolae (Qucstio ab universitate Hafniensi ad solvendum proposita et proemio ornata). Copenhagen: Librariae Wahlianae.

Ørsted, A. S. (1844). Zur Classification der Annulaten mit Beschreibung einiger neuer oder unzulänglich bekannter Gattungen und Arten. Arch. Naturgeschichte Berlin 10, 99-112.

Pettibone, M. H. (1963). Marine polychaete worms of the New England region. 1. Families Aphroditidae through Trochochaetidae. U.S. Natl. Mus. Bull. 227, 1-356. doi: 10.5479/si.03629236.227.1

Pettibone, M. H. (1982). "Annelida," in Synopsis and Classification of Living Organisms, ed S. P. Parker (New York, NY: McGraw-Hill), 1-43.

Pleijel, F. (2001). "Sphaerodoridae Malmgren, 1867," in Polychaetes, eds G. W. Rouse and F. Pleijel (Oxford: Oxford University Press), 136-138.

Pleijel, F., and Dahlgren, T. (1998). Position and delineation of Crysopetalidae and Hesionidae (Annelida, Polychaeta, Phyllodocida). Cladistics 14, 129-150. doi: 10.1111/j.1096-0031.1998.tb00327.x

Purschke, G., and Müller, M. C. M. (2006). Evolution of body wall musculature. Integr. Comp. Biol. 46, 497-507. doi: 10.1093/icb/icj053

Rathke, H. (1843). Beiträge zur Fauna Norwegens. Breslau: Verhandlungen der Kaiserlichen Leopoldinisch-Carolinischen Akademie Naturforscher.

Reimers, H. (1933). Morphologie der polychaetengattung sphaerodorum. monographie. Zool. Jahrb. Abt. Syst. Ökol. Geogr. Tiere 64, 41-110.

Reuscher, M., and Fiege, D. (2011). Sphaerodoridae (Annelida: Polychaeta) from the deep south-west Pacific, with the description of a new species of Sphaerodoropsis. J. Mar. Biol. Assoc. U.K. 91, 439-445. doi: 10.1017/S0025315410000469

Rieger, R. M. (1991). Neue Organisationstypen aus der Sandlückenfaune: die Lobatocerebriden und Jennaria pulchra. Verh. Dtsch. Zool. Ges. 84, 247-259.

Rouse, G. W., and Fauchald, K. (1997). Cladistics and polychaetes. Zool. Scr. 26, 139-204. doi: 10.1111/j.1463-6409.1997.tb00412.x

Ruderman, L. (1911). Recherches sur Ephesia gracilis Rathke, Annélide polychète de la famille des sphaerodorides; morphologie, anatomie, histology. Mém. Soc. Zool. France 24, 1-96.

Russell, D. E. (1991). Exogoninae (Polychaeta: Syllidae) from the Belizean barrier reef with a key to species of Sphaerosyllis. J. Nat. Hist. 25, 49-74. doi: 10.1080/00222939100770061

Saint-Joseph, A. (1894). Les Annelides polychetes des cotes de Dinard. Troisieme partie. Ann. Sci. Nat. Zool. Paleontol. Ser. 7, 1-395.

Salazar-Vallejo, S. I., Carrera-Parra, L. F., and Fauchald, K. (2008). Phylogenetic affinities of the Flabelligeridae (Annelida, Polychaeta). J. Zool. Syst. Evol. Res. 46, 203-215. doi: 10.1111/j.1439-0469.2008.00464.x

San Martín, G. (1984). Estudio Biogeografico, Faunistico y Systematico de los Poliquetos de la Familia Silidos (Polychaeta: Syllidae) en Baleares. Tesis Doctoral, Univ. Complutense Madrid.

San Martín, G. (2003). "Annelida Polychaeta: II, Syllidae," in Fauna Iberica, Vol. 21, ed M. A. Ramos (Madrid: CSIC, Museo Nacional de Ciencias Naturales), 554.

San Martín, G., Hutchings, P., and Aguado, M. T. (2008). Syllinae (Polychaeta: Syllidae) from Australia. Part 2. Genera Inermosyllis, Megasyllis n. gen., Opisthosyllis and Trypanosyllis. Zootaxa 1840, 1-53.

Sardá-Borrroy, R. (1987). Sphaerodoridae (Annelida, Polychaeta) from the region of the Gibraltar Strait with description of Euritmia hamulisetosa gen. et sp. n. Zool. Scr. 16, 47-50. doi: 10.1111/j.1463-6409.1987.tb00051.x 
Schmarda, L. K. (1861). Neue Wirbellose Thiere Beobachtet und Gesammelt auf Einer Reise un die Erdr 1853 bis 1857. Erster Band (zweite halfte) Turbellarian, Rotatorien un Anneliden. Leipzig: Wilhelm Engelmann.

Storch, V. (1968). Zur vergleichenden Anatomie der segmentalen Muskelsysteme und zur Verwandtschaft der Polychaeten-Familien. Z. Morph. Tiere 63, 251-342. doi: 10.1007/BF00292073

Tzetlin, A. B., and Filippova, A. (2005). "Muscular system in polychaetes (Annelida)," in Morphology, Molecules, Evolution and Phylogeny in Polychaeta and Related Taxa, Vol. 535/536, Hydrobiologia, eds G. Purschke and T. Bartolomaeus (Dordrecht: Springer), 113-126.

Tzetlin, A., and Purschke, G. (2005). "Pharynx and intestine," in Morphology, Molecules, Evolution and Phylogeny in Polychaeta and Related Taxa, Vol. 535/536, Hydrobiologia, eds G. Purschke and T. Bartolomaeus (Dordrecht: Springer), 199-225.

Wanninger, A., Koop, D., Bromham, L., Noonan, E., and Degnan, B. M. (2005). Nervous and muscle system development in Phascolion strombus (Sipuncula). Dev. Genes Evol. 215, 509-518. doi: 10.1007/s00427-005-0012-0

Webster, H. E., and Benedict, J. E. (1887). The Annelida Chaetopoda, from Eastport, Maine. Annu. Rep. U.S. Comm. Fish Fish. Washington 1885, 707-758.

Weigert, A., Helm, C., Meyer, M., Nickel, B., Arendt, D., Hausdorf, B., et al. (2014). Illuminating the base of the annelid tree using transcriptomics. Mol. Biol. Evol. 31, 1391-1401. doi: 10.1093/molbev/msu080

Wilson, R. (2000). "Family Sphaerodoridae," in Polychaetes and Allies: The Southern Synthesis. Fauna of Australia, Vol. 4, Polychaeta, Myzostomida, Pogonophora, Echiura, Sipuncula, eds P. Beesley, G. Ross, and C. J. Glasby, (Melbourne: CSIRO Publishing), 160-161.
Worsaae, K., Nygren, A., Rouse, G. W., Giribet, G., Persson, J., Sundberg, P., et al. (2005). Phylogenetic position of Nereillidae and Aberranta (Polychaeta, Annelida), analysed by direct optimisation of combined molecular and morphological data. Zool. Scr. 34, 313-328. doi: 10.1111/j.1463-6409.2005. 00190.x

Zrzavý, J., Ríha, P., Piiálek, L., and Janouskovec, J. (2009). Phylogeny of Annelida (Lophotrochozoa): total-evidence analysis of morphology and six genes. BMC Evol. Biol. 9:189. doi: 10.1186/1471-2148-9-189

Conflict of Interest Statement: The authors declare that the research was conducted in the absence of any commercial or financial relationships that could be construed as a potential conflict of interest.

Received: 24 September 2014; accepted: 24 December 2014; published online: 13 January 2015.

Citation: Helm C and Capa M (2015) Comparative analyses of morphological characters in Sphaerodoridae and allies (Annelida) revealed by an integrative microscopical approach. Front. Mar. Sci. 1:82. doi: 10.3389/fmars.2014.00082

This article was submitted to Marine Systematics and Taxonomy, a section of the journal Frontiers in Marine Science.

Copyright (C) 2015 Helm and Capa. This is an open-access article distributed under the terms of the Creative Commons Attribution License (CC BY). The use, distribution or reproduction in other forums is permitted, provided the original author(s) or licensor are credited and that the original publication in this journal is cited, in accordance with accepted academic practice. No use, distribution or reproduction is permitted which does not comply with these terms. 